\title{
Activation of Locus Coeruleus from Nucleus Paragigantocellularis: A New Excitatory Amino Acid Pathway in Brain
}

\author{
Matthew Ennis ${ }^{\mathrm{a}}$ and Gary Aston-Jones \\ Department of Biology, New York University, New York, New York 10003
}

\begin{abstract}
Recent anatomic and physiologic experiments revealed that a major afferent to the nucleus locus coeruleus (LC) is the nucleus paragigantocellularis (PGi) in the rostral ventrolateral medulla (Aston-Jones et al., 1986). In the present studies, responses of LC neurons to electrical activation of PGi were characterized in anesthetized rats. Low-intensity stimulation of PGi synaptically activated $73 \%$ of LC neurons at short latencies (mean onset, $11.3 \mathrm{msec}$ ), while a smaller population (16\%) of LC neurons exhibited purely inhibitory responses. The excitatory transmission from PGi to LC was pharmacologically analyzed, revealing it to be resistant to cholinergic receptor antagonism, but completely abolished by the excitatory amino acid (EAA) antagonists kynurenic acid and $\gamma$-D-glutamylglycine. The specific $\boldsymbol{N}$-methyl-D-aspartate antagonist 2-amino-7-phosphonoheptanoic acid (AP7) and the preferential quisqualate receptor antagonist glutamate diethyl ester (GDEE) did not block LC responses to PGi stimulation, leading us to the tentative conclusion that EAAs may operate primarily at a kainate-type receptor on LC neurons to effect excitation from PGI. In addition to their blockade of PGi-evoked activity, kynurenic acid and DGG exerted a similar, simultaneous blockade of the characteristic excitation of LC neurons evoked by electrical stimulation of the hindpaw. These and other results indicate that the proposed EAA pathway from PGi may serve as a final link in a variety of sensory inputs to LC.
\end{abstract}

Our recent anatomic and physiologic investigations of afferents to locus coeruleus (LC) revealed that this globally projecting noradrenergic nucleus receives afferents from remarkably few brain loci (Aston-Jones et al., 1986). One of the major afferents to $\mathrm{LC}$, as revealed by retrograde transport of wheat germ agglutinin-conjugated horseradish peroxidase (WGA-HRP), is the nucleus paragigantocellularis (PGi; Andrezik et al., 1981a) in the ventrolateral medulla. This projection has been confirmed with retrograde transport of rhodamine-labeled latex microspheres (Guyenet and Young, 1987; V. A. Pieribone and G. Aston-Jones, unpublished observations) and of Fluoro-Gold

Received Aug. 10, 1987; revised Dec. 16, 1987; accepted Dec. 16, 1987

This work was supported by PHS Grant MH09381, BRSG Grant RR07062, the Spencer Foundation, ONR Contract N00014-86-K-0493, the Air Force Office of Scientific Research, and the Alzheimer's Disease and Related Disorders Association. We thank Dr. John Lehmann for helpful discussions and Klaus Liebold, Floyd Bloom, Mike Palmer, and Barry Hoffer for computer software.

Correspondence should be addressed to Gary Aston-Jones, Department of Biology, New York University, 1009 Main Building, Washington Square, New York, NY 10003.

"Present address. Department of Physiology, University of Cincimati College of Medicine ML-576, Cincinnati, OH 45267.

Copyright (C) 1988 Society for Neuroscience $0270-6474 / 88 / 103644-14 \$ 02.00 / 0$
(Pieribone et al., 1988), as well as with anterograde transport of WGA-HRP (Aston-Jones et al., 1986) and Phaseolus vulgaris leucoagglutinin (Guyenet and Young, 1987).

Recent physiologic studies in this laboratory have also confirmed projections to LC from PGi: focal electrical stimulation of $\mathrm{LC}$ antidromically activates numerous neurons in the PGi but not cells in neighboring structures (Ennis and Aston-Jones, 1987). Those experiments also revealed marked physiologic heterogeneity for PGi cells projecting to $\mathrm{LC}$, and 2 groups of neurons were distinguished on the basis of extracellular impulse waveforms, spontaneous rate, conduction velocity, and anatomical location within PGi. Consistent with these results for physiologically distinct groups of PGi neurons afferent to LC, our preliminary investigation of synaptic transmission in this pathway revealed 2 effects of PGi activation on LC discharge: predominant excitation and, in a minority of cells, inhibition (Ennis and Aston-Jones, 1986a).

Although the neurochemical identity of PGi neurons afferent to LC has not been fully characterized, immunohistochemical and receptor binding studies indicate that many neurotransmitters may impinge on LC neurons (see Foote et al., 1983, for review), and pharmacologic studies reveal that discharge of LC neurons is sensitive to a variety of neurotransmitters (Foote et al., 1983). It is noteworthy that the diverse neurochemical innervation of LC is paralleled by a multiplicity of neurotransmitter markers among PGi neurons (Hökfelt et al., 1974, 1977; Chan-Palay, 1977; Ljungdahl et al., 1978; Armstrong et al., 1982; Swanson et al., 1983; Butcher and Woolf, 1984; Kimura et al., 1984). In light of these findings, it secms reasonable to speculate that PGi may provide multiple neurotransmitter innervation of LC and that physiologically and perhaps neurochemically distinct groups of LC-projecting cells in PGi may provide different regulatory influences on $\mathrm{LC}$.

One method of identifying neurotransmitters utilized in projections from PGi neurons is the combination of retrograde transport and immunocylochemical techniques. However, such an approach does not disclose the functional impact of afferent neurotransmitters on LC discharge. In the present studies, we have used electrical stimulation, extracellular recordings, and pharmacologic techniques to characterize the regulatory control exerted by this ventrolateral medullary afferent on LC activity. Our results identify the PGi as a major, potent excitatory influence on LC neuronal discharge and reveal that excitation of LC from PGi is mediated by an amino acid neurotransmitter. These overall findings identify a previously unknown excitatory amino acid pathway in the CNS and characterize a major component in neural circuits providing control of the globally projecting, LC noradrenergic system. Some of these data have been reported elsewhere (Ennis and Aston-Jones, 1986a). 


\section{Materials and Methods}

Male Sprague-Dawley rats (270-370 gm) were anesthetized with chloral hydrate or halothane. For chloral hydrate anesthesia $(n=30)$, an initial dose of $400 \mathrm{mg} / \mathrm{kg}$ was given intraperitoneally (ip), and additional doses were administered as needed. Halothane-anesthetized animals $(n=24)$ received $0.5-1.0 \%$ in air via spontaneous respiration. Animals were intubated with a tracheal cannula and placed in a stereotaxic frame with the incisor bar lowered to place the skull approximately $24^{\circ}$ from the horizontal plane. Body temperature was maintained at $36-37^{\circ} \mathrm{C}$ with a thermistor-controlled heating pad.

Stimulation electrode implantation. The tissue and muscles of the neck at the caudal dorsal skull margin were reflected, and the occipital bone over the caudal cerebellum was removed. The underlying dura was reflected to revcal the obcx. To place clcctrodes in PGi rcliably, wc found it helpful to guide dorsoventral placement with respect to the ventral brain surface as follows. A micropipette was aligned over midline and the rostral edge of the obex under microscopic control. From this position, the pipette was moved $2.0-2.3 \mathrm{~mm}$ rostral and $1.9-2.1 \mathrm{~mm}$ lateral and was lowered through the cerebellum into the medulla. The depth of ventral brain surface (revealed by a sharp increase in noise in unfiltered pipette records) was noted. Typically, a group of neurons exhibiting prominent discharge with respiration was encountered within $1-1.5 \mathrm{~mm}$ of the ventral brain surface. The pipette was removed and a stimulation electrode was implanted at the same coordinates, except for being 500-700 $\mu \mathrm{m}$ above the ventral brain surface (typically $6.5-$ $7.5 \mathrm{~mm}$ ventral to cerebellar surface). Stimulation electrodes consisted of a pair of twisted $250-\mu \mathrm{m}$ - (47 animals) or $150-\mu \mathrm{m}$-diameter (5 animals) wires, insulated except for bluntly cut tips. In addition, two 26 gauge needles were placed subcutaneously in the medial contralateral rear footpad for electrical stimulation of the sciatic nerve. Electrical stimuli were bipolar pulses $(0.5 \mathrm{msec}$ duration) from a square-wave stimulator (Grass S48) and a constant-current stimulus isolation unit (Grass PSIU6). Logic pulses synchronized with brain or footpad stimuli (FS) were led to a computer for on-line peristimulus time histogram (PSTH) generation.

$L C$ recordings. A $3-\mathrm{mm}$-diameter hole was drilled in the skull above LC (4.7 mm caudal to lambda, and $1.2 \mathrm{~mm}$ lateral to midline), and the dura was reflected. Extracellular recordings from individual neurons were obtained with glass micropipettes (2-4 $\mu \mathrm{m}$ tip diameter, $10-20$ $\mathrm{M} \Omega$ impedance) filled with $2 \%$ pontamine Sky blue dye in $0.5 \mathrm{M}$ sodium acetate. Micropipette recordings were amplified (Grass model P16), displayed continuously on a storage oscilloscope as unfiltered and filtered $(500 \mathrm{~Hz}-10 \mathrm{KHz}$ bandpass) signals, and also monitored with a loudspeaker. Action potentials were isolated from background activity with a waveform discriminator, which generated output pulses for signals that crossed a lower voltage gate, peaked below an upper voltage gate, and passed through a time window at a preset voltage and delay. The discriminator output was led to the computer and a chart recorder for on-line data collection.

Micropipettes were stereotaxically advanced into LC (approximately 5.8-6.5 mm ventral to skull surface) ipsilateral to the PGi stimulation site, and LC neurons were tentatively identified by their characteristic notched waveform, slow and regular discharge $(0.5-4 \mathrm{spikes} / \mathrm{sec})$, and a biphasic excitation-inhibition response sequence evoked by FS (Fig. $2 D$ ) or by pressure applied to the scalp incision. After stable recordings from an individual LC neuron were obtained, an interspike interval histogram (ISH) was generated for 1.5-3 min of spontaneous activity. Neuronal responses to single-pulse PGi stimulation were examined and threshold for synaptic activation (driving on approximately half the stimuli) was determined. A PSTH of LC response to PGi stimulation was generated for 50 consecutive stimuli presented at $0.5 \mathrm{~Hz}$ and 1.5 2 times threshold (up to $1.2 \mathrm{~mA}$ ). A similar PSTH was taken for FS $(20-70 \mathrm{~V})$. These same measures were repeated $1.5-3.0 \mathrm{~min}$ after drug administration.

Pharmacology. Aqueous solutions of the following drugs were administered systemically: idazoxan $(0.1-1.0 \mathrm{mg} / \mathrm{ml})$, mecamylamine hydrochloride $(0.5 \mathrm{mg} / \mathrm{ml})$, scopolamine hydrochloride $(0.5 \mathrm{mg} / \mathrm{ml})$, naloxone hydrochloride $(0.5 \mathrm{mg} / \mathrm{ml})$, methiothepin $(0.25 \mathrm{mg} / \mathrm{ml})$, and dihydroergotamine tartrate $(0.1 \mathrm{mg} / \mathrm{ml})$. Excitatory amino acid (EAA) antagonists do not readily cross the blood-brain barrier and were injected intracerebroventricularly (icv). These agents were dissolved in $0.1 \mathrm{M}$ phosphate buffer, yielding the following concentrations: $0.02 \mathrm{M}$ ( \pm ) 2-amino-7-phosphonoheptanoate (AP7; Institut National de Recherche Chimique Appliquée, France), 2.95 m glutamate diethyl ester hydrochloride (GDEE), $0.2 \mathrm{M} \gamma$-D-glutamylglycine (DGG), and $0.1 \mathrm{M}$ kynurenic acid. Solutions of these agents were prepared daily and their $\mathrm{pH}$ was adjusted to between 6.5 and 8.0. For icv drug administration, a 23 gauge guide cannula was implanted in a lateral ventricle $(1.0 \mathrm{~mm}$ caudal to bregma, $1.5 \mathrm{~mm}$ lateral to midline, $4.0 \mathrm{~mm}$ ventral to skull surface) and secured to skull screws with dental cement. Drugs were injected through a 30 gauge cannula, extending out of the previously implanted guide cannula by approximately $1 \mathrm{~mm}$. Intravenous (iv) injections were made in a lateral tail vein. Unless otherwise noted, all drugs were obtained from Sigma Chemical Co.

Histology. Micropipette penetrations were marked by iontophoretic ejection of dye with negative current pulses ( $7 \mu \mathrm{A}, 50 \%$ duty cycle for $10 \mathrm{~min}$ ). At the end of recording sessions, $30 \mu \mathrm{A}$ of positive current was passed through the stimulation electrode for $1 \mathrm{~min}$ to deposit iron at the electrode tips. A $5 \mu \mathrm{l}$ bolus of neutral red was injected through the inner cannula to confirm ventricular placement. Animals were then deeply anesthetized and perfused with $10 \%$ formaldehyde in $0.1 \mathrm{~m}$ phosphate buffer containing $5 \%$ potassium ferrocyanide. The ferrocyanide in this perfusate yields a visible prussian blue reaction product at the site of the iron deposit (see Fig. 1A). Brains were removed and stored in a similar solution containing $10 \%$ sucrose. Select brain regions were cut in $50-\mu$ m-thick sections with a freezing microtome, mounted on gelatinized glass slides, and stained with neutral red. All stimulation, recording, and ventricular infusion sites were histologically localized from such tissue sections (Fig. 1).

Data analysis. ISHs and PSTHs were used to examine spontaneous discharge and evoked responses, respectively. To quantitate evoked responses, individual PSTHs were analyzed by computer to determine excitatory and inhibitory epochs. A baseline period was defined as the $500 \mathrm{msec}$ epoch preceding stimulation, and the mean and SD of counts per baseline bin were determined. The onset of significant excitation was defined as the first of 5 consecutive bins ( $8 \mathrm{msec}$ bin width) whose mean value exceeded mean baseline activity by 2 SD, and response offset was determined as the time at which activity had returned to be consistently within $2 \mathrm{SD}$ of baseline. The following equation was used to normalize response magnitudes for differing baseline activity and to calculate the magnitude of excitatory responses $\left(R_{\text {mag }}\right)$ :

$$
\begin{aligned}
R_{\text {mag }}- & \text { (counts in excitatory epoch) } \\
& - \text { (mean counts per baseline bin } \\
& \times \text { no. bins in excitatory epoch). }
\end{aligned}
$$

Excitation onset and offset times were used to define the "excitatory epoch" in PSTHs; this same excitatory epoch was used to calculate $R_{\text {mas }}$ for postdrug PSTHs in which excitation was totally blocked. Inhibition was defined by computer as an epoch of at least 15 bins in which the mean count per bin was less than $35 \%$ of that during baseline. Except where otherwise noted, data were statistically analyzed by paired $t$ test.

\section{Results}

Data are reported for 218 histologically verified LC neurons (Fig. $1 B$ ). As all or nearly all rat LC neurons contain norepinephrine (Swanson, 1976; Grzanna and Molliver, 1980), the data reported here are for known noradrenergic neurons.

\section{Excitatory responses from PGi}

As shown in Figure 2 and summarized in Table 1, single-pulse, low-intensity PGi stimulation yielded phasic, excitatory responses in the majority of LC neurons at onset latencies ranging from 9 to $40 \mathrm{msec}$. In 13 chloral hydrate-anesthetized rats, such stimulation excited $28 / 38$ cells at a mean onset latency $( \pm$ SEM) of $11.7 \pm 1.3 \mathrm{msec}$ and duration of $32.8 \pm 3.1 \mathrm{msec}$; the mean threshold for excitation was $345 \mu \mathrm{A}$. These results are similar to those we previously reported for PGi-induced excitation of LC neurons in chloral hydrate-anesthetized rats. For example, the mean excitatory onset latency found here is identical to that previously determined (11.7 msec; Ennis and Aston-Jones, 1986a), and the ovcrall percentages of cells exhibiting excitatory and inhibitory responses (below) are comparable in the 2 studies. Thus, we have pooled these data as shown in the first row in Table 1. Responses of 29 LC neurons to PGi stimulation in 7 halothane-anesthetized rats were similar to those in chloral hy- 

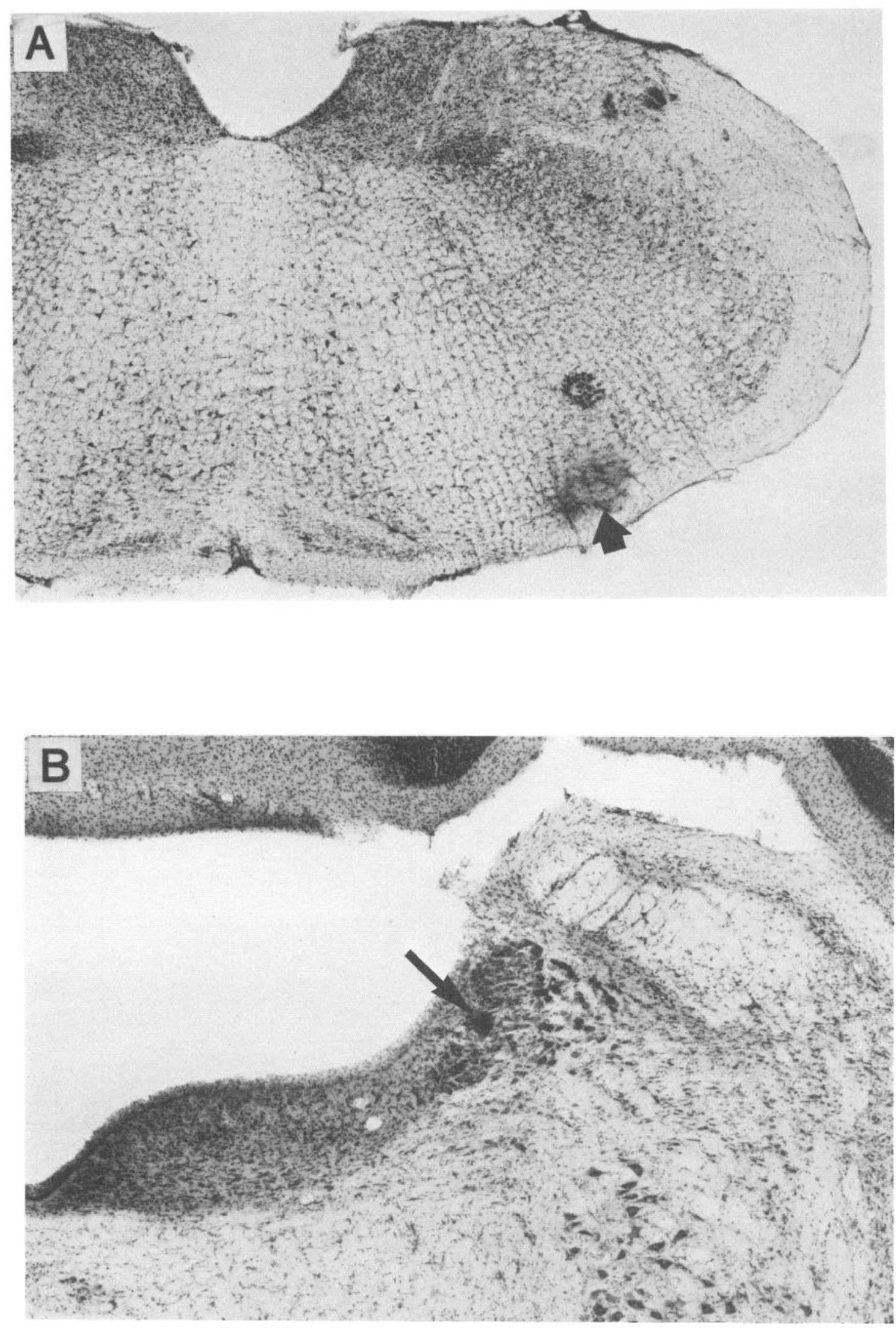

Figure 1. Histological analyses. A, Photomicrograph of a 50- $\mu$ m-thick coronal section (Neutral red stain) taken through the rostral medulla. Prussian blue mark (dark area in ventral medulla, arrow) reveals stimulation site in PGi. Dorsal is at top, midline is to the left. B, Photomicrograph of a 50- $\mu \mathrm{m}$-thick coronal section taken through LC. Iontophoretic injection of pontamine sky blue (dark spot, arrow) marks the location of recording micropipette in LC. Length of arrow in $A, 253 \mu \mathrm{m}$; in $B, 268 \mu \mathrm{m}$. 


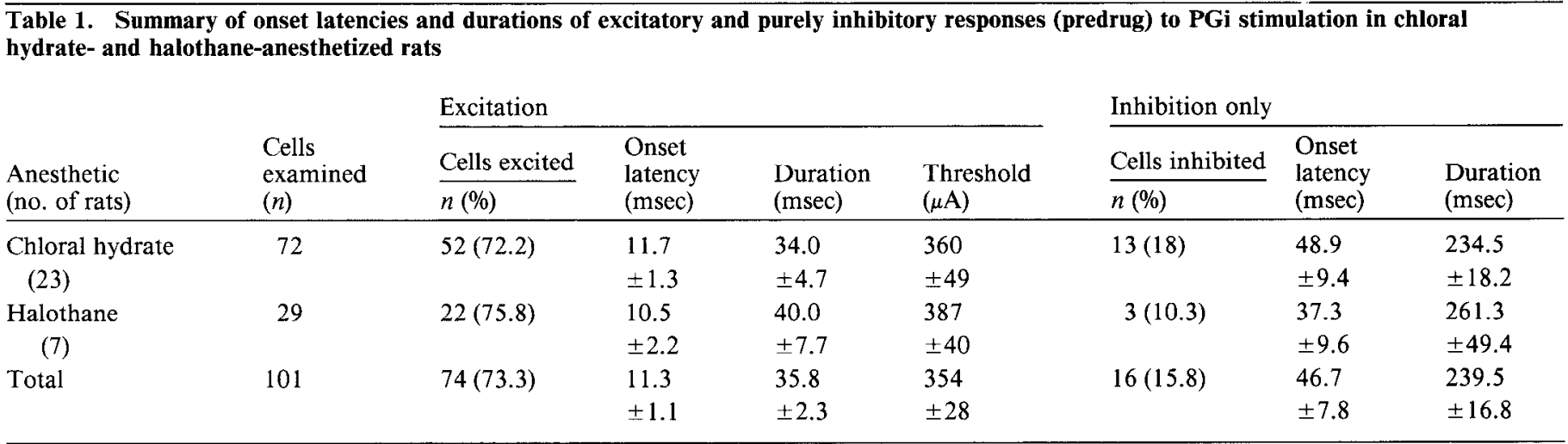

All values are means \pm SEM.

drate-anesthetized rats (see Table 1). Overall, 74 of 101 (73\%) LC neurons were significantly excited by PGi stimulation. Neurons throughout the LC nucleus were activated from PGi, and there did not appear to be topographic specificity within LC for excitation elicited by PGi stimulation.

PGi-evoked excitation was typically followed by inhibition lasting 200-600 msec, characteristic of that observed for LC neurons following activation by synaptic, antidromic, or intracellular stimuli (Cedarbaum and Aghajanian, 1978; Aghajanian and VanderMaelen, 1982; Ennis and Aston-Jones, 1986b). Postactivation inhibition appears to be a phenomenon intrinsic to the LC, and studies in our laboratory and others indicate that postactivation inhibition is mediated by intracoerulear collaterals and intrinsic membrane currents secondary to action potential generation (Andrade and Aghajanian, 1983; Ennis and $\Lambda$ ston-Jones, 1986b). Thus, such postactivation may be largely mediated by local feedback mechanisms secondary to synaptic excitation from PGi. In addition, the duration of postactivation inhibition observed after PGi- or FS-evoked excitation of LC neurons was typically several hundred milliseconds longer than pure inhibitory responses evoked from PGi stimulation (see below).

In additional experiments, the effects of increasing stimulation intensity (up to twice the 1.5-2.0 times threshold used to generate PSTHs) on excitation of 29 LC neurons (19 rats) was examined. Raising stimulation current had no overall effect upon excitation magnitude $(p>0.5)$. Instead, it was noted that response magnitude increased for some cells examined, while in others excitation was reduced. When neurons were grouped according to the direction of change elicited in response magnitude, analyses revealed that higher PGi stimulation intensity significantly increased excitation magnitude in 8 cells $(p<0.01)$, decreased the magnitude in 11 cells $(p<0.01)$, and completely attenuated excitation in 6 additional cells.

\section{Control stimulation electrode placements}

The ability to activate LC'neurons was critically dependent upon stimulation electrode placement. Stimulation through electrodes locatcd in arcas outside PGi yiclded littlc or no LC activation. For example, electrode placement on the ventral brain surface below rostral PGi (1 rat) activated only 1 of 9 LC cells, and only at a relatively high intensity $(600 \mu \mathrm{A})$. Only 1 of 7 cells (1 rat) was activated from stimulation $(425 \mu \mathrm{A})$ of the medullary reticular formation $700 \mu \mathrm{m}$ dorsal to PGi. Electrode placements in the lateral reticular nucleus $1.5-2.5 \mathrm{~mm}$ caudal to PGi (1 rat) failed to activate any of $12 \mathrm{LC}$ neurons, even at stimulation currents up to $2.0 \mathrm{~mA}$. Overall, a greater percentage of LC neurons were activated from stimulation electrodes confined to PGi than from placements on the edge of PGi: while only 11/ $24 \mathrm{LC}$ neurons (46\%) were activated from the LRN-PGi border, $25 / 33$ cells $(76 \%)$ were activated from electrodes centered in PGi.

\section{Pharmacologic tests}

The overall results of the pharmacologic analysis of excitation from PGi are summarized in Figure 8 and Table 2 below.

\section{Excitatory amino acid antagonists}

Previous studies reveal that LC neurons are potently excited by glutamate (Guyenet and Aghajanian, 1979; Engberg et al., 1981; Chouvet et al., 1988) and NMDA (Lacey and Henderson, 1986). We therefore examined the ability of EAA antagonists to attenuate PGi-induced excitation of LC neurons.

Kynurenic acid. As we previously reported (Ennis and AstonJones, 1986a), and as shown in Figures 2, $A$ and $B$, and 8, the broad spectrum EAA antagonist kynurenic acid (Perkins and Stone, 1982) completely blocked PGi-induced excitation in all 5 LC neurons tested $(0.53 \mu \mathrm{mol}$, icv, $p<0.01)$. Excitation from PGi stimulation was totally blocked within 1.5-3.0 min after kynurenic acid injection.

Kynurenic acid simultaneously had a similar effect on FS responses in LC (Figs. 2, $D, E ; 8$ ), totally attenuating such excitation in all 4 LC neurons examined $(p<0.001)$.

In 2 cells tested, excitatory responses to PGi or FS stimulation could not be elicited after kynurenic acid administration even at stimulation intensities above those yielding significant predrug excitation, indicating that the kynurenate effect was not the result of a simple change in the threshold for excitation.

A single dose of kynurenic acid appeared to be effective for about $60 \mathrm{~min}$, as PGi- and FS-elicited responses recovered in 2 cells examined 40-70 min after administration of this agent (Fig. 2, $C, F$ ). Also, PGi stimulation was found to excite other LC neurons examined 60-90 min after kynurenic acid administration.

Finally, while kynurenic acid had profound effects on PGiand FS-induced activity in LC neurons (as described above), it did not significantly alter spontaneous discharge rate of LC neurons (although a tendency to decrease discharge rate was noted).

$D G G$. The EAA antagonist DGG, which preferentially blocks 


\section{PGi Stim.}
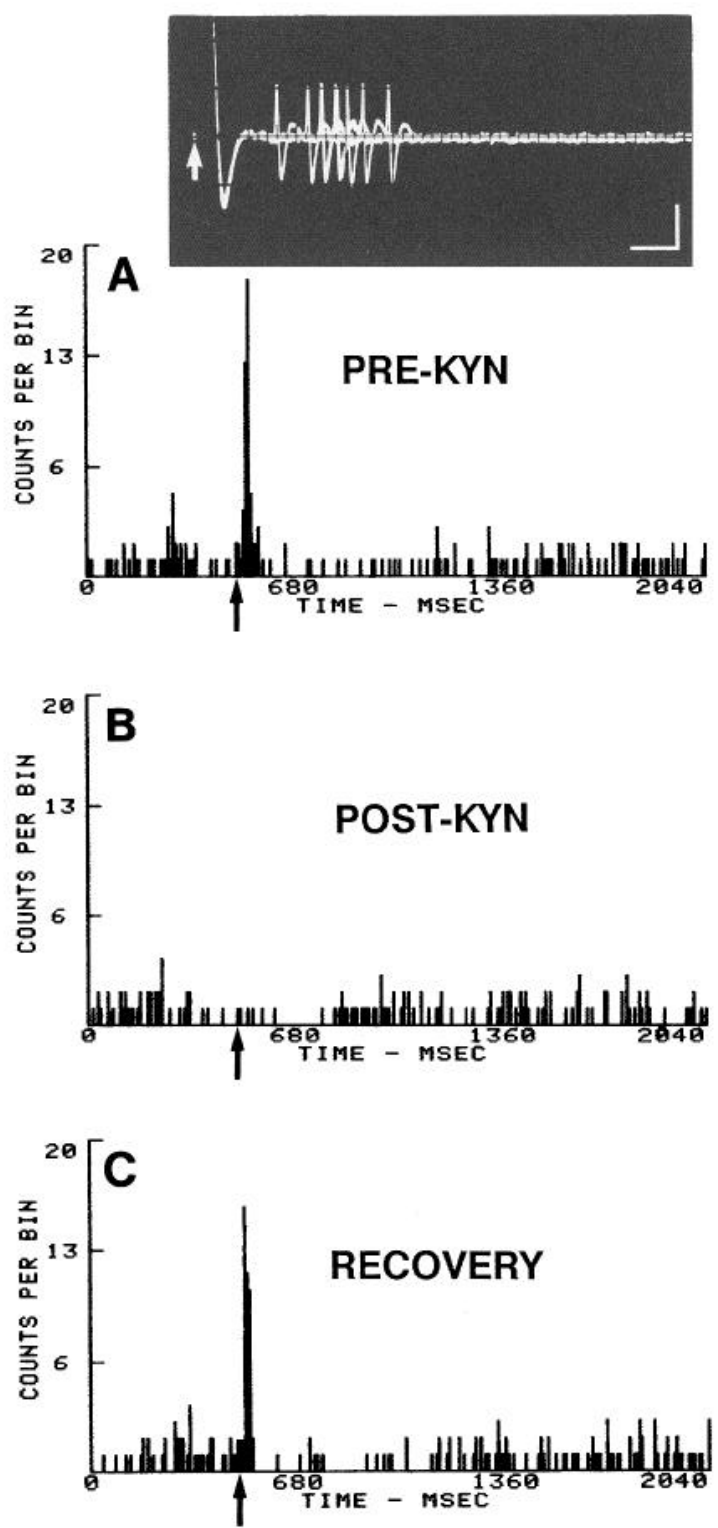

FS
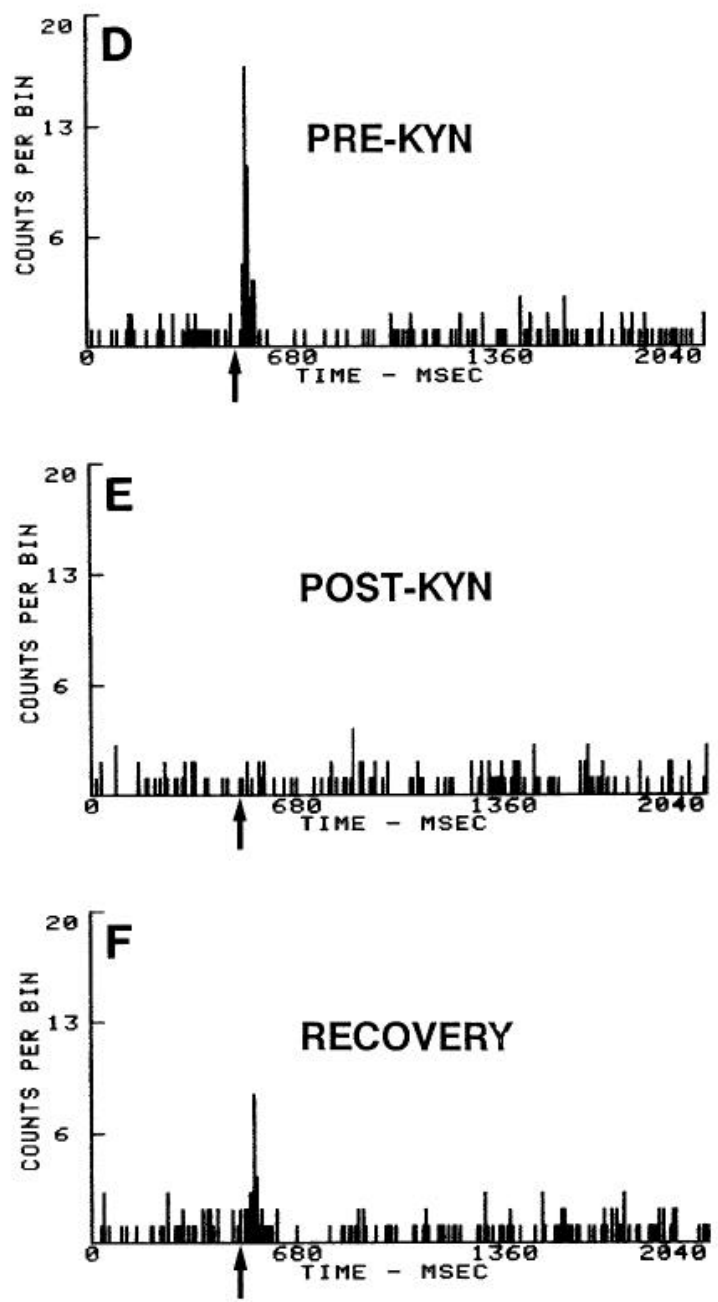

Figure 2. Blockade of PGi-induced $(A-C)$ or FS-induced $(D-F)$ excitation of LC neurons by kynurenic acid $(K Y N)$. $A$, Typical example of a PSTH generated during $0.5 \mathrm{~Hz}$, single-pulse electrical stimulation of PGi. Stimulation indicated by arrow in this and all subsequent PSTHs. Such stimulation yielded potent, short-latency excitation of this LC neuron (bins containing driven spikes are seen shortly after arrow). Excitation is followed by a longer-lasting inhibition of impulse activity, similar to the characteristic postactivation inhibition of LC neurons (Aghajanian et al., 1977; Cedarbaum and Aghajanian, 1978; Ennis and Aston-Jones, 1986b). Inset, Photograph of 10 superimposed oscilloscope sweeps (filtered records) showing PGiinduced activation of another LC neuron. Single-pulse stimulation (at arrow, $750 \mu \mathrm{A}, 1.5 \times$ threshold) of PGi activated this cell at latencies ranging from 8 to $19 \mathrm{msec}$. Calibrations: $5.0 \mathrm{msec}, 0.5 \mathrm{mV}$. B. Similar PSTH for PGi stimulation (same cell and stimulation intensity as in $A$ ), but 1.5 min after $0.53 \mu \mathrm{mol} \mathrm{KYN} \mathrm{(icv).} \mathrm{Note} \mathrm{that} \mathrm{KYN} \mathrm{completely} \mathrm{attenuates} \mathrm{PGI-induced} \mathrm{excitation} \mathrm{of} \mathrm{this} \mathrm{LC} \mathrm{neuron.} C$, PSTH for the same cell as in $A$ and $B$ showing recovery of PGi-evoked excitation 70 min after KYN administration. Stimulation intensity in $A-C, 300 \mu \mathrm{A}$. $D$, PSTH showing FS-induced excitation of the same LC neuron as in $A-C$. E, FS-elicited excitation is completely abolished 3 min after the dose of KYN $(0.53 \mu$ mol, icv) that also blocked PGi-evoked excitation of this cell. $F$, PSTH showing partial recovery of FS responses by 54 min after KYN administration. Stimulation intensity in $D-F, 20 \mathrm{~V}$. All PSTHs were generated for 50 consecutive stimuli, presented at $0.5 \mathrm{~Hz}$.

NMDA and kainate receptors (Francis et al., 1980; Davies and Watkins, 1981), also potently antagonized PGi-induced excitation of LC neurons (Figs. 3, $A, B ; 8$ ). As shown in Figure 4, DGG $(0.1-1.0 \mu \mathrm{mol}$, icv) produced a dose-dependent reduction of PGi-evoked excitation, significantly attenuating evoked responses in LC neurons at $0.1 \mu \mathrm{mol}(n=5, p<0.005)$. Excitation was completely blocked in all cells tested with $0.32 \mu \mathrm{mol}(n=$ $4, p<0.02$ ).

DGG also simultaneously decreased FS excitation in a dosedependent manner (Figs. 3, $C, D ; 8$ ); the minimum dose for such attenuation was $0.18 \mu \mathrm{mol}(n=5, p<0.02)$. Regression analysis revealed a strong inverse correlation between FS ex- 


\section{PGi Stim.}
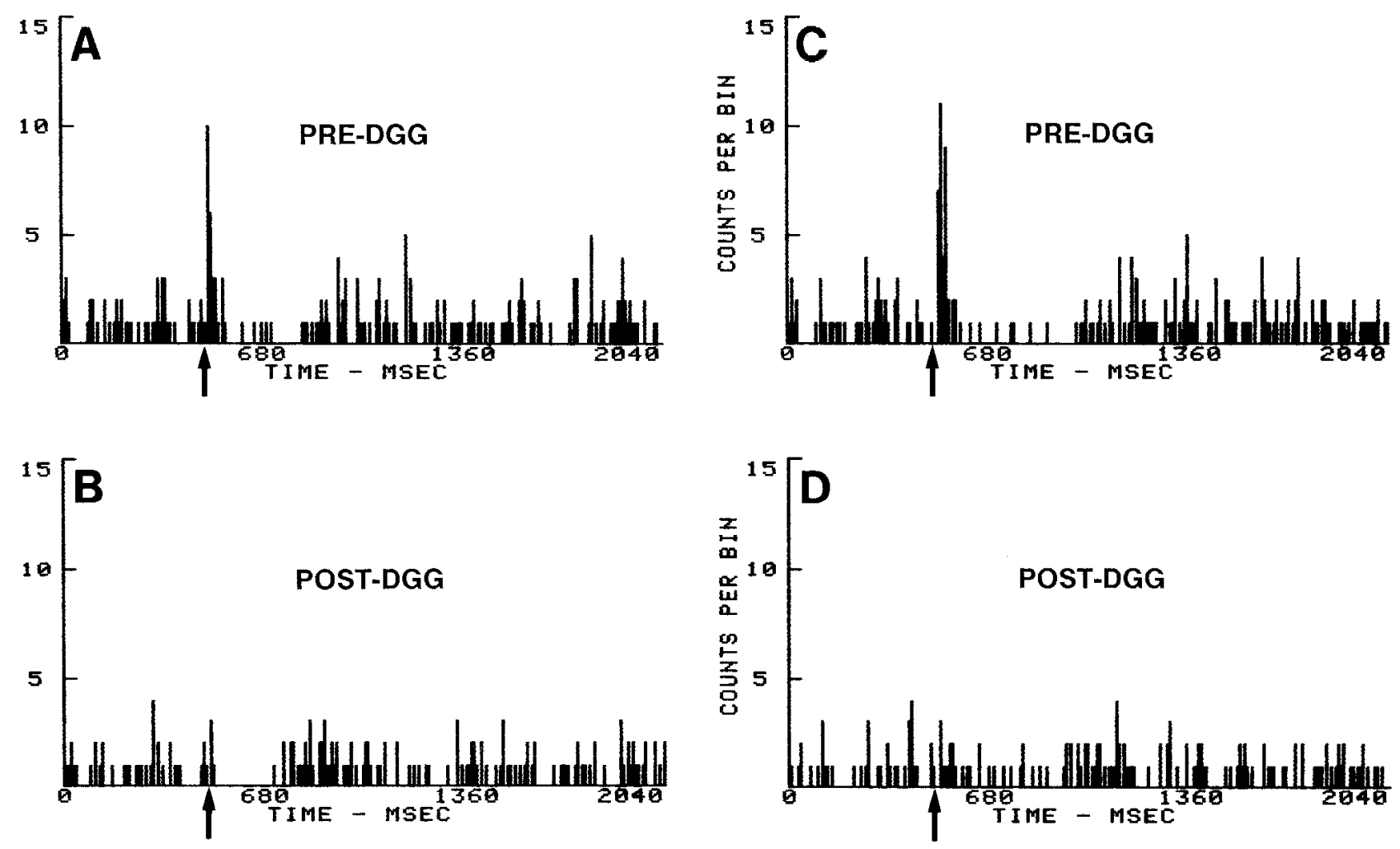

Figure 3. Blockade of PGi- and FS-induced excitation of LC neurons by DGG. $A$, PSTH showing PGi-evoked excitation of an LC neuron. $B$, PSTH for the same cell, revealing that excitation shown in $A$ is completely blocked $1.5 \mathrm{~min}$ after $0.32 \mu$ mol DGG (icv). Note purely inhibitory response of this neuron to PGi stimulation is revealed after blockade of excitation by DGG. Stimulation intensity in $A$ and $B$, $600 \mu A$. Similarly, after this same dose of DGG, FS-evoked excitation of this same cell (C, predrug) was simultaneously and completely abolished, $(D, 3$ min postdrug). Stimulation amplitude in $C$ and $D, 40 \mathrm{~V}$. Stimuli (50 in each PSTH) at arrows.

citation magnitude in LC neurons and dose of DGG administered $(R=-0.67, p<0.001)$. Overall, however, FS responses of LC neurons appeared more resistant to DGG than responses to PGi stimulation For example, while PGi-induced excitation was totally blocked in all cells following $0.32-1.0 \mu \mathrm{mol} D G G$, excitation from FS was blocked in only $4 / 7$ of these neurons. In contrast, kynurenic acid completely blocked all excitation from both PGi and FS in all cells examined (described above). In addition to attenuating FS-evoked excitation of LC neurons, both kynurenic acid and DGG also inhibited activation of LC neurons by other stimuli, such as tail or foot pinch.

In addition to attenuating PGi- and FS-evoked activation, DGG reduced spontaneous activity somewhat (Fig. 8), with the discharge rate of $6 \mathrm{LC}$ neurons examined decreasing from 2.4 \pm 0.3 before to $1.7 \pm 0.2$ spikes/sec after DGG in the range of $0.32-1.0 \mu \mathrm{mol}(p<0.05)$. However, DGG-induced alterations in spontaneous activity are unable to account for the attenuation of evoked activity by this agent, both because the decrease in spontaneous activity was modest and because our calculated response magnitudes are normalized for alterations in spontaneous discharge (see Materials and Methods).

$G D E E$. In contrast to the pronounced attenuation of both PGi- and FS-elicited excitation of LC neurons by kynurenic acid and DGG, a high dose of GDEE $(15 \mu \mathrm{mol})$, the preferential quisqualate receptor antagonist (Watkins, 1981; Davies et al., 1984), did not significantly attenuate PGi-induced excitation ( $n$
$=5, p>0.25$; Figs. $5, A, B ; 8$ ). Although excitation was blocked in 1 cell, this was accompanied by a large increase in spontaneous rate, which may reduce $\mathrm{LC}$ responsiveness (Valentino and Aulisi, 1987; Valentino and Foote, 1987; discussed below).

As with PGi-evoked responses, GDEE did not alter overall excitation elicited by FS ( $n=5, p=0.45$; Fig. 8 ) and did not block FS excitation in any individual cell (Fig. $5, C, D$ ).

Finally, although GDEE injection elicited a transient increase in discharge in some cells (lasting $1-4 \mathrm{~min}$ ), this agent had no significant overall effect on spontaneous rate $(n=4, p>0.10)$.

$A P 7$. Intracerebroventricular injection of $0.1 \mu \mathrm{mol}$ of the sclective NMDA receptor antagonist AP7 (Evans et al., 1982) had no significant effect on overall excitation of LC neurons by PGi stimulation ( $n=7, p>0.10$; Figs. $6, A, B ; 8$ ). Although this agent blocked excitation in 2 of 7 neurons tested, this was accompanied by an increase in spontaneous discharge, which may itself blunt responsiveness (Valentino and Aulisi, 1987; Valentino and Foote, 1987; discussed below).

AP7 was found to reduce FS-elicited excitation of LC neurons ( $n=10, p<0.004)$; however, as illustrated for a typical cell in Figure 6, $C$ and $D$, AP7 did not completely block FS excitation in any of the 10 cells tested, and the overall decrease in FS excitation by this agent was much weaker than that elicited by kynurenic acid or DGG (Fig. 8). Furthermore, as illustrated in Figure $6 E$, the decrease in FS-elicited excitation in 5 of 6 cells was accompanied by an increase in spontaneous rate, an effect 


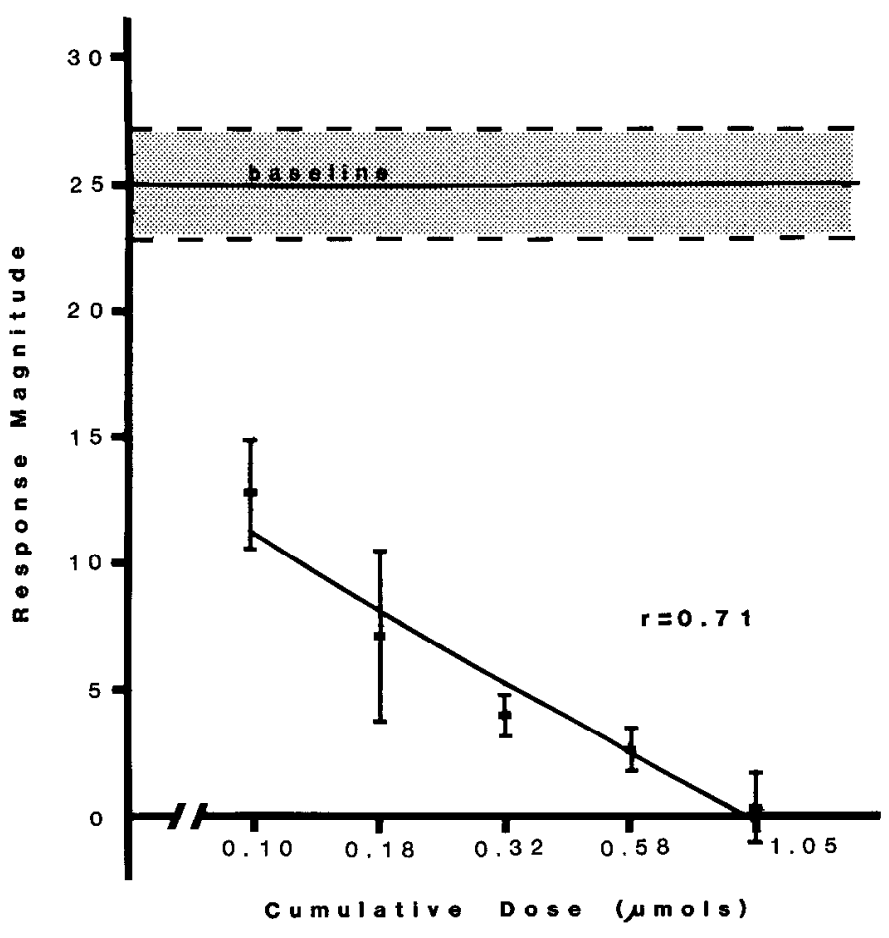

Figure 4. Log dose-response plot of the effect of DGG on PGi-evoked excitation of LC neurons. Each point represents mean excitation response magnitude \pm SEM calculated for data collected from at least 4 cells. As illustrated, DGG in doses from 0.1 to $1.05 \mu \mathrm{mol}$, icv, attenuated $\mathrm{PGi}$-evoked excitation in a dose-dependent manner $(R=-0.71, p<$ 0.001 , regression analysis). Regression line is plotted from these data. Mean pre-DGG baseline response magnitude is shown at upper solid horizontal line; stippling indicates SEM.

which itself may reduce the excitability of LC cells (Valentino and Aulisi, 1987; Valentino and Foote, 1987; see below). Overall, however, AP7 did not significantly increase spontaneous rate $(p>0.05)$.

Vehicle. Administration of vehicle alone $(5 \mu \mathrm{l}$ of $0.1 \mathrm{M}$ phosphate buffer, icv) had no effect on PGi- $(n=5, p>0.35)$ or FS-elicited excitation $(n=4, p>0.65)$ of LC neurons. However, when injected rapidly (in 10-20 sec), such vehicle administration elicited a transient $(0.5-3 \mathrm{~min})$ increase in spontaneous discharge.

\section{Cholinergic agents}

Previous work has provided evidence for an excitatory, cholinergic innervation of the LC (Guyenet and Aghajanian, 1979; Rotter et al., 1979; Albanese and Butcher, 1980; Engberg and Svensson, 1980). In addition, neurons in the PGi area stain for cholinergic markers (Butcher and Woolf, 1984; Kimura et al., 1984). We therefore tested the ability of the muscarinic antagonist scopolamine and the nicotinic antagonist mecamylamine to reduce $\mathrm{PGi}$-evoked activation of $\mathrm{LC}$ neurons.

Scopolamine. We have previously reported (Ennis and AstonJones, 1986a) that intravenous or intraperitoneal administration of scopolamine, at doses that antagonize muscarinic cholinergic excitation of LC neurons (Guyenet and Aghajanian, 1979; Engherg and Svensson, 1980), had only minor, nonsignificant effects overall on excitatory responses of $\mathrm{LC}$ neurons to PGi stimulation. As shown in Figure 7, $A, B$, for a typical cell, scopolamine did not significantly attenuate PGi-induced excitation of LC $(n=5, p>0.50)$, although scopolamine did block excitation in 1 of 5 cells tested. Scopolamine $(0.5 \mathrm{mg} / \mathrm{kg}$, iv) was also ineffective on FS responses of LC neurons (Fig. 8; $n=$ 7 cells in 3 rats, $p>0.50$ ), and this agent did not block FSevoked excitation in any of the 7 cells tested. Scopolamine at this dose did not alter the spontaneous discharge rate of LC neurons ( $n=7, p>0.45$ ).

Mecamylamine. We further examined the possible cholinergic mediation of excitatory responses with the nicotinic receptor antagonist mecamylamine. As shown in Figures 7, $C, D$, and 8 , $1.0 \mathrm{mg} / \mathrm{kg}$ mecamylamine (iv) did not antagonize excitation in any of 7 LC neurons ( 5 rats, $p>0.10$ ). Similarly, mecamylamine had no overall effect on FS responses (Fig. $8 ; n=5, p>0.05$ ), although such excitation was significantly decreased in one LC neuron. Mecamylamine had no effect on the spontaneous discharge rate of LC neurons $(n=5, p>0.10)$.

\section{LC excitatory responses and spontaneous activity}

In the course of these experiments, we noted an inverse relationship between the magnitude of excitatory, evoked responses and spontaneous discharge rate. Injection (iv or icv) of agents that elicited an increase in spontaneous discharge was typically associated with a decrease in the excitatory response of LC neurons from both PGi stimulation and FS. This trend was observed for some cells following the administration of AP7 (Fig. 7, C-E), GDEE, scopolamine, mecamylamine, and vehicle ( $0.1 \mathrm{M}$ phosphate buffer, icv), especially when these agents were administered rapidly or in large volumes. Usually the decrease in excitatory response magnitudes was relatively small (Fig. 7E); however, in some cases (typically accompanied by a large increase in spontaneous discharge), excitation was completely blocked or severely attenuated. It is noteworthy that the actions of kynurenic acid and DGG were in contrast to this general pattern; these agents tended to decrease spontaneous rate, while they dramatically attenuated or completely blocked PGi- and FS-evoked excitation of LC neurons.

\section{Pure inhibition from PGi}

Purely inhibitory responses to PGi stimulation (Fig. 9) were observed in $16 / 101$ or approximately $16 \%$ of LC cells. This inhibition occurred at a longer onset latency $(46.7 \pm 7.8 \mathrm{msec})$ than that for excitatory responses and was also longer in duration $(239.5 \pm 16.8 \mathrm{msec})$. It should be noted that in 6 of these cells purely inhibitory responses were observed at relatively long latencies (48-112 $\mathrm{msec}$ ), and a small but nonsignificant excitation appeared to precede such inhibition, while 10 other cells exhibited shorter onset latencies (from 12 to $32 \mathrm{msec}$ ) for pure inhibition with no apparent prior excitation.

Interestingly, pharmacologic blockade of PGi-evoked excitation in LC revealed an underlying purely inhibitory response in most post-kynurenate and post-DGG PSTHs. Thus, icv administration of kynurenic acid or DGG (Fig. 3B) disclosed a purely inhibitory response to PGi stimulation in (respectively) $5 / 5$ and $5 / 8$ cells that were originally excited by the same stimulation prior to drug administration.

Excitatory and purely inhibitory responses could be evoked in different $\mathrm{LC}$ neurons from the same stimulation site in PGi. In addition, both excitatory and purely inhibitory responses were elicited from stimulation of various rostrocaudal and mediolateral regions of PGi. Stimulation sites centrally located within PGi were associated with the highest percentage of synaptically activated neurons and the lowest percentage of inhibited cells. 


\section{PGi Stim.}
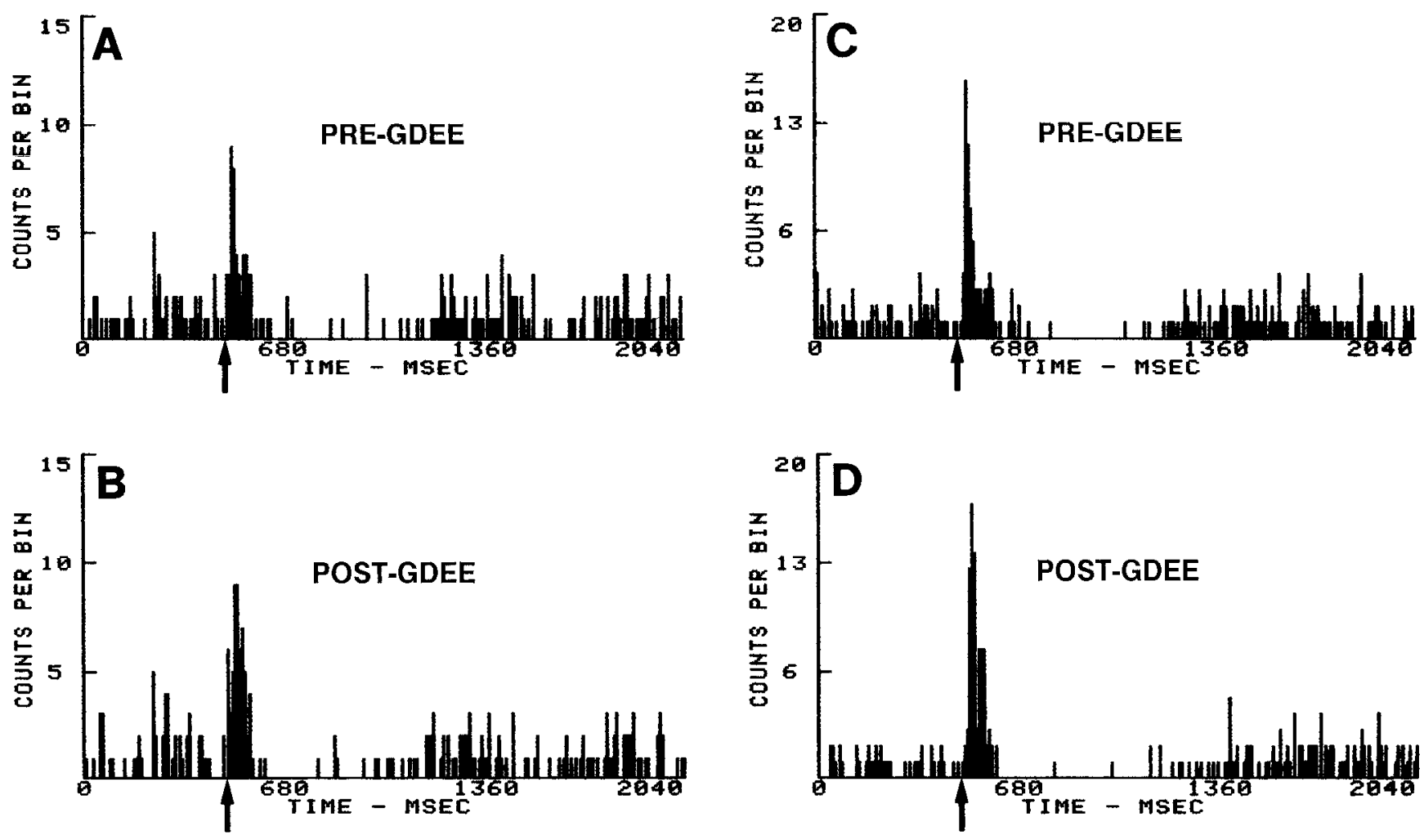

Figure 5. Lack of effect of GDEE on PGi- and FS-evoked excitation. $A$ and $B$, PSTHs of LC responses to PGi stimulation before $(A)$ and after $(B)$ GDEE. Activation of this LC neuron from PGi (shown in $A$ predrug; $700 \mu$ A stimulation) is not attenuated 4 min after administration of 15 $\mu$ mol GDEE (icv), as shown $\mathrm{n} B$ postdrug. $C$ and $D$, Similar PSTHs of LC activity taken during FS before $(C)$ and after $(D)$ GDEE administration. FS-evoked excitation (40 V stimulation) of the same cell, shown in $C$ predrug, is not decreased but is slightly enhanced by this dose of GDEE, shown for FS 2 min after GDEE in $D$. Fifty stimuli (at arrows) in each PSTH.

Eleven of the $101 \mathrm{LC}$ cells (11\%) examined were not significantly affected by PGi stimulation.

\section{Discussion}

This work represents the first comprehensive physiologic investigation of an anatomically identified input to LC. Our results provide additional evidence for strong innervation of LC by PGi and reveal that this projection is predominantly excitatory on LC discharge. The present pharmacologic results indicate that this excitation may be mediated by an EAA.

\section{Evoked responses from PGi}

Several findings indicate that excitatory responses in $\mathrm{LC}$ evoked by PGi stimulation were monosynaptically evoked and were not due to activation of fibers of passage or activation of indirect circuits to LC. (1) Low-intensity, single-pulse PGi stimulation potently activated $\mathrm{LC}$ within a narrow range of latencies. (2) Latencies for synaptic activation of LC neurons from PGi (mean onset, $11.3 \mathrm{msec}$ ) are similar to those for antidromic activation of PGi neurons from LC (mean, $8.6 \mathrm{msec}$; Ennis and AstonJones, 1987). (3) Stimulation through electrodes located in LRN, caudal to PGi, was ineffective on LC discharge. Similarly, electrode placements dorsal, rostroventral to PGi, or on the borders of PGi were minimally effective in synaptically activating LC neurons.
The observation that a small percentage of LC cells exhibit purely inhibitory responses to PGi stimulation suggests that LC may receive both excitatory and inhibitory sets of $P G i$ afferents. Indeed, we observed a purely inhibitory response to PGi stimulation in nearly all LC neurons after blocking excitation with the EAA antagonists DGG (Fig. $3 B$ ) or kynurenic acid. Thus, the predominant response to PGi stimulation after kynurenic acid or DGG is pure inhibition. We have not pharmacologically characterized such inhibition; however, it may be related to direct adrenergic projections from PGi to LC. Recent experiments in our laboratory have shown that a minority (approximately $21 \%$ ) of PGi neurons retrogradely labeled from LC also stain for phenylethanolamine- $N$-methyltransferase, the final synthetic enzyme for adrenaline (Pieribone et al., 1988). As adrenaline applied directly to LC neurons is strongly inhibitory (Cedarbaum and Aghajanian, 1976, 1977), it is possible that the minor inhibitory influence on LC neurons from PGi found here may correspond to this adrenergic pathway to $\mathrm{LC}$.

It is also possible that at least some of the observed inhibition results from activation of collaterals of other $\mathrm{LC}$ neurons that are excited by PGi. Anatomic and physiologic findings (Swanson, 1976; Aghajanian et al., 1977; Cedarbaum and Aghajanian, 1978; Shimizu et al., 1979; Groves and Wilson, 1980) suggest that such inhibitory collateral interactions regulate $\mathrm{LC}$ neuronal activity, with recent results indicating that this mechanism may 


\section{PGi Stim.}

FS
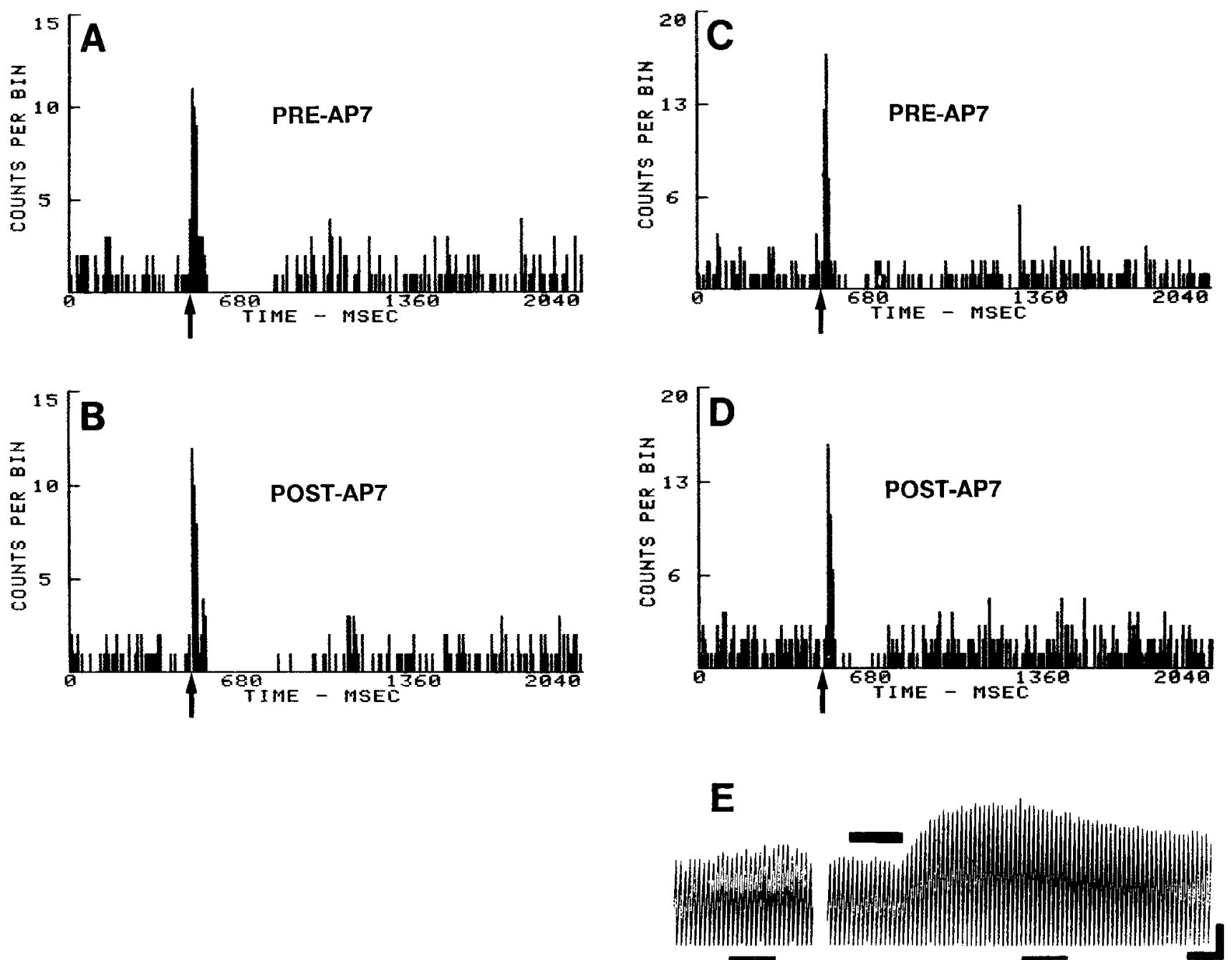

Figure 6. Effects of AP7 (0.1 $\mu \mathrm{mol}$, icv) on PGi and FS responses and on spontaneous discharge. $A$ and $B$, PSTHs depicting LC responses to PGi stimulation before $(A)$ and after $(B)$ AP7 administration. PGi-evoked excitation of an LC cell shown in $A$ predrug, is not affected by AP7 administration, shown 1.5 min after AP7 in $B$. Stimulation intensity in $A$ and $B, 400 \mu \mathrm{A}$. $C$ and $D$, PSTHs of responses of an LC neuron to FS before $(C)$ and after $(D)$ AP7. FS-evoked activation of this LC neuron, shown in $C$ predrug, is slightly decreased after a similar dose of AP7, as illustrated in $D 6 \mathrm{~min}$ post-AP7. Note that response magnitudes were calculated as the difference between evoked and baseline activity (see Materials and Methods). Therefore, the decrease in FS-elicited excitation in $D$ partially results from the increase in spontaneous discharge rate $(E)$. Stimulation intensity in $C$ and $D, 40 \mathrm{~V}$. Stimuli are presented at arrows. Each PSTH contains activity accumulated over 50 consecutive trials. $E$, Chart rccording of impulse activity (integrated over $10 \mathrm{sec}$ epochs) for the cell illustrated in $C$ and $D$, showing an increase in discharge rate after administration (at upper bar) of $0.1 \mu \mathrm{mol}$ AP7, icv. Lower bars indicate where pre-AP7 (left bar) and post-AP7 (right bar) FS histograms were collected ( $C$ and $D$, respectively). Calibration: horizontal bar, $80 \mathrm{sec}$; vertical bar, 10 spikes.

be effective even on LC neurons that are not themselves activated (Ennis and Aston-Jones, 1986b; however, also see Andrade and Aghajanian, 1984).

In predrug experiments, pure inhibitory responses from PGi stimulation were occasionally preceded by a small, nonsignificant excitation for some cells. Such preceding impulse activity may have partially mediated the observed inhibition via intracoerulear inhibitory mechanisms. The shorter pure inhibitory onset latencies observed in cells without apparent prior excitation may be a more accurate representation of the onset latency for direct, pure inhibition from PGi.

Increasing stimulation current above that yielding significant excitation was found to reduce or abolish excitation from PGi in some LC cells. This finding can be interpreted in terms of collateral-mediated postactivation inhibition, such that increased stimulation intensity synaptically activates a greater number of cells, yielding collateral inhibition that may predominate over excitatory inputs to some LC cells. Alternatively, higher stimulation intensity may activate additional, direct inhibitory projections to LC from PGi.

Previous studies in behaving rats have revealed that $L C$ neurons are excited by a wide range of sensory stimuli (Aston-Jones and Bloom, 1981). The similarity of these responses across modalities led to the proposal that they may be mediated polysynaptically, through a final common set of afferents to LC (AstonJones et al., 1984; Aston-Jones, 1985). The present results for 

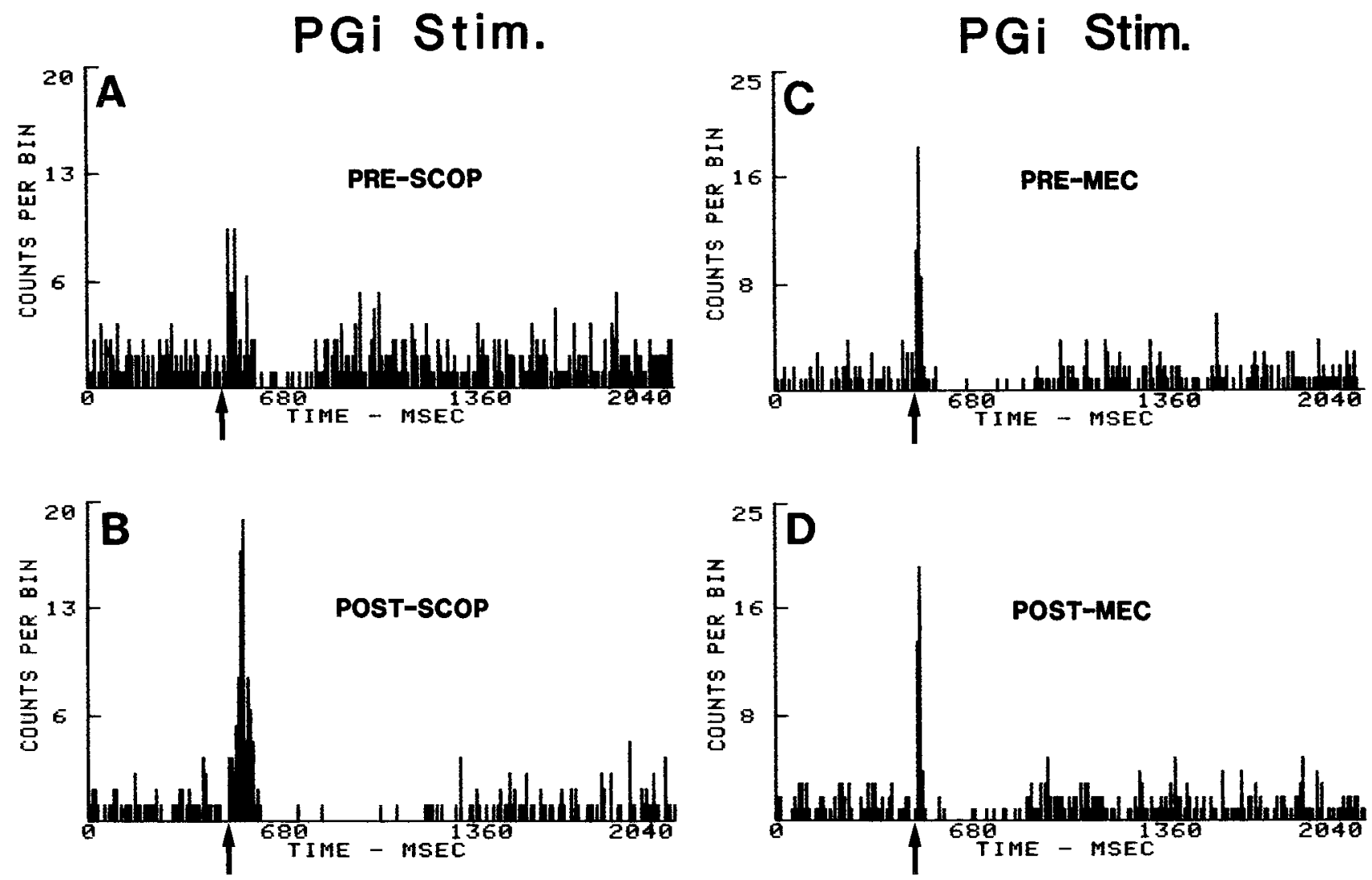

Figure 7. Cholinergic receptor antagonists scopolamine ( $S C O P ; A$ and $B$ ) and mecamylamine $(M E C ; C$ and $D)$ fail to block PGi-evoked excitation of LC neurons. $A$ and $B$, PGi-evoked excitation of an LC neuron, shown in $A$ predrug, is not attenuated but is facilitated $4 \mathrm{~min}$ after $0.5 \mathrm{mg} / \mathrm{kg}$ SCOP (iv), as illustrated in $B$. $C$ and $D$, PGi-evoked excitation of another LC neuron, shown in $C$ predrug, is not affected 1.5 min after MEC (1.0 $\mathrm{mg} / \mathrm{kg}$, iv), as shown in $D$. All PSTHs contain 50 sweeps. Stimuli are presented at arrows. Stimulation amplitude in all PSTHs, $650 \mu \mathrm{A}$.

predominant excitation of LC from PGi, and our preliminary findings that the single other major input to LC, nucleus prepositus hypoglossi (PrH; identified by retrograde transport of WGA-HRP; Aston-Jones et al., 1986) yields concerted inhibition of LC discharge (Ennis et al., 1987), suggest that such sen- sory responses in LC may be mediated through PGi (AstonJones et al., 1986; Aston-Jones, 1988). This hypothesis is consistent with previous anatomic studies that demonstrate multimodal sensory innervation of PGi (Andrezik et al., 1981b) and with the recent finding that local anesthesia of PGi blocks

Table 2. Effects of pharmacologic agents on mean spontaneous rate ( \pm SEM) and mean excitatory response magnitudes $( \pm$ SEM) of $L C$ neurons for PGi stimulation and FS

\begin{tabular}{|c|c|c|c|c|c|c|c|c|c|}
\hline \multirow[b]{2}{*}{ Drug (dose) } & \multicolumn{3}{|c|}{ PGi response magnitude } & \multicolumn{3}{|c|}{ FS response magnitude } & \multicolumn{3}{|c|}{ Spontaneous rate } \\
\hline & $\begin{array}{l}\text { Cells } \\
(n)\end{array}$ & Pre drug & Post drug & $\begin{array}{l}\text { Cells } \\
\text { (n) }\end{array}$ & Pre drug & Post drug & $\begin{array}{l}\text { Cells } \\
(n)\end{array}$ & Pre drug & Post drug \\
\hline $\begin{array}{l}\text { Kynurenic acid } \\
\quad(0.53 \mu \mathrm{mol}, \mathrm{icv})\end{array}$ & 5 & $\begin{array}{l}26.8 \\
\pm 3.9\end{array}$ & $\begin{array}{l}-1.8 \\
\pm 1.9^{* *}\end{array}$ & 5 & $\begin{array}{l}42.9 \\
\pm 1.5\end{array}$ & $\begin{array}{l}2.0 \\
\pm 0.6^{* * *}\end{array}$ & 4 & $\begin{array}{l}2.2 \\
\pm 0.2\end{array}$ & $\begin{array}{l}1.9 \\
\pm 0.4\end{array}$ \\
\hline $\begin{array}{l}\text { DGG } \\
\qquad(1.0 \mu \mathrm{mol}, \mathrm{icv})\end{array}$ & 5 & $\begin{array}{l}27.2 \\
\pm 2.6\end{array}$ & $\begin{array}{l}0.1 \\
\pm 1.4^{* * * *}\end{array}$ & 5 & $\begin{array}{l}43.4 \\
\pm 8.2\end{array}$ & $\begin{array}{l}11.0 \\
\pm 2.3^{* *}\end{array}$ & $6^{a}$ & $\begin{array}{l}2.4 \\
\pm 0.3\end{array}$ & $\begin{array}{l}1.7 \\
\pm 0.2^{*}\end{array}$ \\
\hline $\begin{array}{l}\text { GDEE } \\
\qquad(15 \mu \mathrm{mol}, \mathrm{icv})\end{array}$ & 5 & $\begin{array}{l}26.0 \\
\pm 4.3\end{array}$ & $\begin{array}{l}21.2 \\
\pm 4.0\end{array}$ & 5 & $\begin{array}{l}36.8 \\
\pm 7.0\end{array}$ & $\begin{array}{l}39.2 \\
\pm 9.0\end{array}$ & 4 & $\begin{array}{l}3.0 \\
\pm 0.7\end{array}$ & $\begin{array}{l}3.8 \\
\pm 0.6\end{array}$ \\
\hline $\begin{array}{l}\text { AP7 } \\
\qquad(0.1 \mu \mathrm{mol}, \mathrm{icv})\end{array}$ & 8 & $\begin{array}{l}24.2 \\
\pm 2.7\end{array}$ & $\begin{array}{l}18.3 \\
\pm 3.9\end{array}$ & 10 & $\begin{array}{l}40.4 \\
\pm 3.0\end{array}$ & $\begin{array}{l}31.5 \\
\pm 3.1^{* * *}\end{array}$ & 7 & $\begin{array}{l}1.8 \\
\pm 0.3\end{array}$ & $\begin{array}{l}2.2 \\
\pm 0.3\end{array}$ \\
\hline $\begin{array}{l}\text { Scopolamine } \\
(0.5 \mathrm{mg} / \mathrm{kg}, \text { iv })\end{array}$ & 5 & $\begin{array}{l}40.4 \\
\pm 6.1\end{array}$ & $\begin{array}{l}43.7 \\
\pm 10.0\end{array}$ & 7 & $\begin{array}{l}33.9 \\
\pm 2.2\end{array}$ & $\begin{array}{l}35.4 \\
\pm 3.2\end{array}$ & 7 & $\begin{array}{l}2.2 \\
\pm 0.4\end{array}$ & $\begin{array}{l}2.1 \\
\pm 0.6\end{array}$ \\
\hline $\begin{array}{l}\text { Mecamylamine } \\
(1.0 \mathrm{mg} / \mathrm{kg}, \mathrm{iv})\end{array}$ & 7 & $\begin{array}{l}23.6 \\
\pm 3.9\end{array}$ & $\begin{array}{l}20.2 \\
\pm 3.6\end{array}$ & 5 & $\begin{array}{l}42.6 \\
\pm 6.9\end{array}$ & $\begin{array}{l}32.4 \\
\pm 3.9\end{array}$ & 5 & $\begin{array}{l}2.5 \\
\pm 0.3\end{array}$ & $\begin{array}{l}2.7 \\
\pm 0.2\end{array}$ \\
\hline
\end{tabular}

Response magnitudes were calculated from the formula: $R_{\operatorname{mag}}=$ (counts in excitatory epoch) - (mean counts per baseline bin $\times$ no. bins in excitatory epoch). ${ }^{*} p<0.05 ;{ }^{* *} p<0.01 ;{ }^{* * *} p<0.005$.

${ }^{a}$ Post-DGG spontaneous rate measurements were obtained from 6 cells after doses of DGG ranging from 0.32 to $1.0 \mu \mathrm{mol}$. 
Figure 8. Bar graph illustrating the effects of pharmacologic agents on PGiand FS-evoked response magnitude $\left(R_{\mathrm{mag}}\right)$ and spontaneous rate of $\mathrm{LC}$ neurons. Scores plotted are percentages of baseline values $( \pm$ SEM $)$. Significance levels are derived from statistical tests of the raw pre- and postdrug data in Table 1. Dotted horizontal line denotes $100 \%$. For drug dosc and ccll numbers tested in each condition, refer to Table 2. ${ }^{*} p<0.05 ;{ }^{* *} p<0.01 ; * * * p<0.005$.

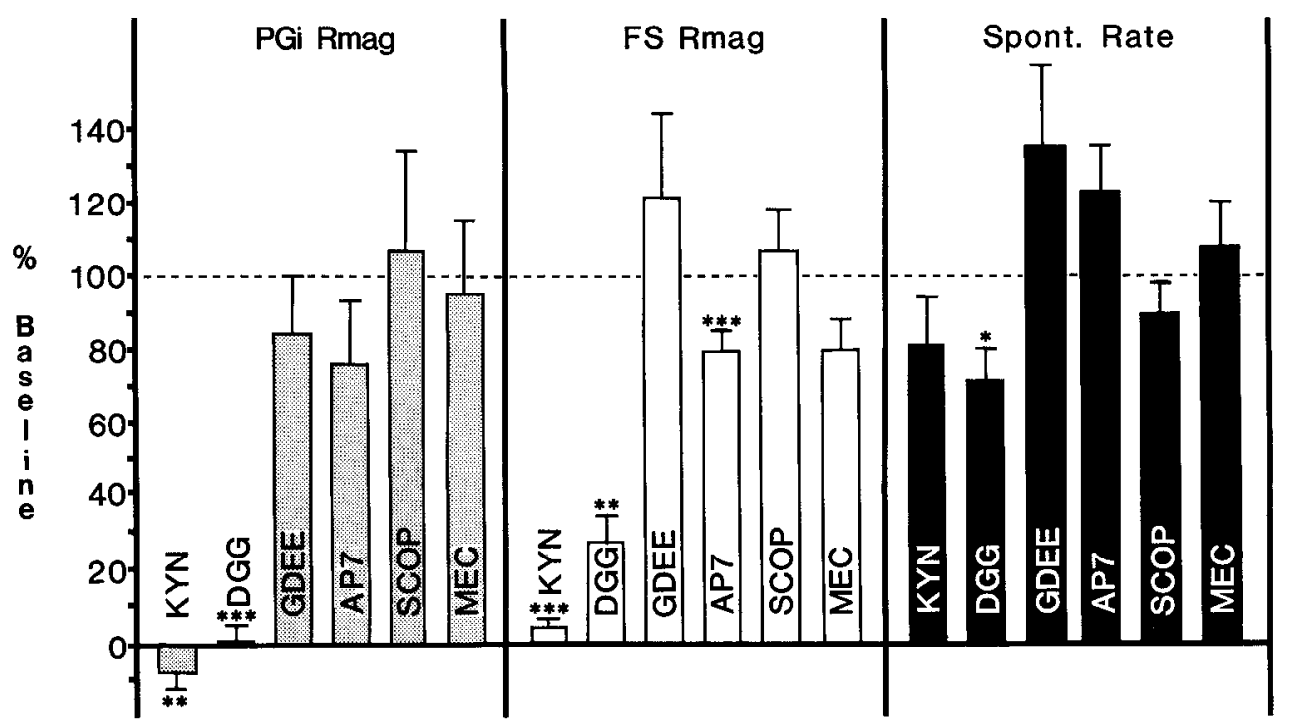

FS-evoked responses in LC (Aston-Jones et al., 1987). Furthermore, LC neurons and PGi neurons that project to LC respond to similar sensory stimuli in anesthetized animals (Ennis and Aston-Jones, 1987).

\section{Pharmacology of excitatory responses}

\section{Excitatory amino acids}

Several investigaticns report potent excitation of LC neurons by direct application of glutamate of NMDA (Guyenet and Aghajanian, 1979; Engberg et al., 1981; Lacey and Henderson, 1986). In addition, EAA-like immunoreactivity has recently been demonstrated in neurons of the PGi area (Forloni et al., 1987; Toomin et al.. 1987). Recent development of agonists and antagonists that delineate specific EAA receptor subtypes facilitates pharmacologic and electrophysiologic examination of EAA transmission. At present, at least 3 EAA receptor subtypes can be identified on the basis of preferential agonists for each subtype: an NMDA-preferring receptor, a kainate-preferring receptor, and a quisqualate-preferring receptor (Watkins, 1981; Davies et al., 1984; Cotman and Monaghan, 1987). NMDA receptor-mediated responses can be specified with selective antagonists available for this receptor, such as AP7 and similar compounds (Evans et al., 1982), while kainate- and quisqualatemediated responses can only be probed with antagonists (such

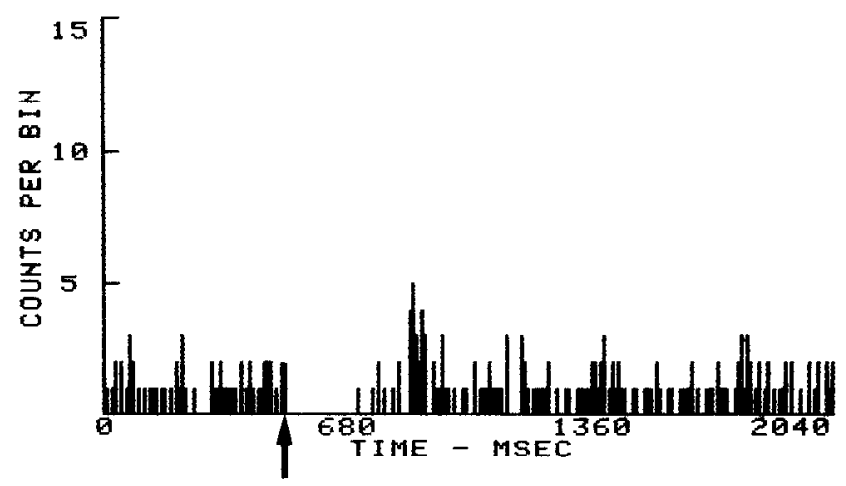

Figure 9. PSTH showing a purely inhibitory response of an LC neuron to PGi stimulation. Stimulation intensity, $650 \mu \mathrm{A}$. Stimuli are presented at arrow. as kynurenic acid, DGG, and GDEE) that are less selective among EAA receptor subtypes.

Kynurcnic acid was initially reported to have little specificity in its antagonism of EAAs or other excitatory transmitters (Perkins and Stone, 1982), yet more recent reports indicate that this agent substantially attenuates NMDA- and kainate-evoked responses but has much less of an effect on quisqualate-evoked responses, especially at low concentrations (Ganong et al., 1983; Perkins and Stone, 1985). DGG exhibits a similar selectivity for NMDA- and kainate-mediated responses, although the antagonistic potency for this agent at these receptors compared with that at the quisqualate receptor varies among studies (Francis et al., 1980; Davies and Watkins, 1981; Collinridge et al., 1983; Surtes and Collins, 1985). In addition, both kynurenic acid and DGG are effective antagonists of possible EAA synaptic transmission in a number of systems (Francis et al., 1980; Ganong et al., 1983; Robinson et al., 1984; Jahr and Yoshioka, 1986). Although there is evidence that GDEE is a preferential quisqualate receptor antagonist, its actions are controversial. For example, while iontophoretically applied GDEE has been reported to be an effective antagonist of quisqualate-evoked responses in the spinal cord (Davies and Watkins, 1979; McLennan and Lodge, 1979), GDEE was without effect on responses to quisqualate, NMDA, or kainate in the hippocampus (Collinridge et al., 1983).

The effectiveness and specificity of EAA antagonists, like other pharmacologic agents, is a function of their concentration at the receptor. Since I.C is a juxtaventricular nucleus, it seems reasonable to assume that the concentration of substances in the CSF would be similar to that in LC. Our findings that ventricularly administered kynurenic acid or DGG attenuate PGiand FS-evoked excitation of LC neurons within $1.5 \mathrm{~min}$ indicate that there may be rapid mixing of ventricularly applied agents in the CSF pool. Thus, to approximate concentrations of EAA antagonists in LC in our experiments and allow comparisons with other studies using these agents, we estimate that the effective CSF pool containing an antagonist (during the $10 \mathrm{~min}$ after injection when tests were performed) was $350 \mu \mathrm{l}: 250 \mu \mathrm{l}$ of ventricular and subarachnoid space (Bass and Lundborg, 1973) and $100 \mu \mathrm{l}$ of diffusion into brain extracellular space (Davson, 1970). Given their lipid insolubility, intracellular volume was 
not included in this analysis. Using this estimate, the dose of kynurenic acid used $(0.53 \mu \mathrm{mol})$ yields a concentration of 1.5 $\mathrm{mm}$ in CSF. In work by others, $0.5 \mathrm{~mm}$ kynurenic acid antagonized excitation by direct application of EAAs (Ganong et al., 1983), and concentrations of 0.13-1.0 mM of this agent attenuated putative EAA-mediated synaptic transmission in some systems (Ganong et al., 1983; Perkins and Stone, 1985; Jahr and Yoshioka, 1986). It should be noted that while kynurenic has been reported to decrease cholinergic-mediated excitation in some studies (Perkins and Stone, 1982), other findings reveal that kynurenic acid has no effect on responses to acetylcholine or cholinergic agonists at doses that attenuate EAA-induced depolarizations or putative EAA-mediated synaptic transmission (Jahr and Yoshioka, 1986; Tsumoto et al., 1986). Also, our finding that cholinergic antagonists do not attenuate PGi-LC excitation makes a possible cholinergic antagonism by kynurenic acid in our experiments unlikely to account for the effects observed.

The determination of possible EAA receptor subtypes mediating synaptic responses often relies on a subtractive approach-comparing the effects of selective NMDA antagonists to effects of EAA antagonists with a broader spectrum of action. Our initial finding that the broad-spectrum EAA antagonist kynurenic acid abolished PGi-evoked excitation of LC indicates that an EAA may mediate this response. The potent ability of the mixed NMDA-kainate antagonist DGG to diminish PGievoked activation of LC in a dose-dependent manner offers further evidence for EAA involvement in this response and, furthermore, suggests mediation by NMDA or kainate receptors. Our estimated concentration of DGG $(0.29-2.9 \mathrm{~mm}$ in CSF) is within the range previously demonstrated to antagonize putative EAA-mediated excitatory postsynaptic potentials (Francis et al., 1980; Crunelli et al., 1987) and also to antagonize primarily excitations induced by kainate or NMDA but not quisqualate (Francis et al., 1980; Surtes and Collins, 1985). For example, in rat olfactory cortex slices, $1 \mathrm{~mm}$ DGG attenuated kainate-evoked responses by $41 \%$, NMDA-evoked responses by $99 \%$, and quisqualate-evoked responses by $17 \%$ (Surtes and Collins, 1985). The lack of involvement of quisqualate receptors in excitation of LC from PGi is also indicated by the ineffectiveness of high doses of the preferential quisqualate antagonist GDEE (43 mm in CSF). In addition, we found that the specific NMDA antagonist AP7, at an estimated dose ( $0.3 \mathrm{~mm}$ in CSF) which is 3 times that shown to antagonize 90\% of NMDAmediated excitation (Evans et al., 1982, Harris et al., 1984), is ineffective overall in blocking LC activation from PGi. Previous work indicates that $\Lambda \mathrm{P} 7$, or 2-amino-5-phosphonoheptanoate, a selective NMDA antagonist with actions similar to AP7 (Evans et al., 1982; Harris et al., 1984; Jones et al., 1984) are over 5 times more effective in attenuating NMDA-evoked excitation that DGG (Jones et al., 1984; Surtes and Collins, 1985). In the present studies, while AP7 $(0.1 \mu \mathrm{mol}$, icv) had no significant effect on PGi-evoked excitation, an identical dose of DGG significantly attenuated such excitation. These findings indicate that NMDA receptors are probably not involved in PGi-evoked excitation of IC and, together with the results above, leads us to propose that an EAA from PGi afferents interacts primarily with a non-NMDA, perhaps kainate-type, receptor on LC neurons.

In preliminary experiments, we have locally infused kynurenic acid in the LC area to test whether icv-administered kynurenic acid in the above studies exerts its actions at the pontine LC level. Initial experiments reveal that PGi- or FS-evoked-activation of LC neurons is abolished after infusion of 5-15 nmol or iontophoresis of kynurenic acid approximately $600 \mu \mathrm{m}$ lateral to LC (M. Ennis and G. Aston-Jones, unpublished observations). These preliminary results indicate that EAA receptor activation on LC neurons may be necessary for PGi- or FSevoked activation of LC neurons.

It is important to note that the ability of EAA antagonists to attenuate PGi-evoked excitation in LC was paralleled by their ability to decrease simultaneously the characteristic activation of LC neurons by sensory stimulation. Thus, kynurenic acid and DGG, but not AP7 or GDEE, dramatically reduced or completely abolished excitation of LC neurons evoked by FS (Fig. 8). Kynurenic acid and DGG also inhibited activation of LC neurons by tail or foot pinch. Although AP7 reduced FS-elicited excitation somewhat, this antagonism was only minor compared with that produced by kynurenic acid or DGG, and AP7 did not completely block FS-elicited excitation in any LC cell tested. This modest antagonism of FS-evoked responses by AP7 may reflect a minor NMDA involvement in circuits afferent to LC or the limited selectivity of AP7 at the relatively high dose used.

We noted, in addition, that the attenuation of FS responses by AP7 was often accompanied by increased spontaneous discharge. This may be a significant observation, as recent studies demonstrate that excitatory responses of LC neurons to synaptic stimuli depend on spontaneous discharge rate, with excitatory responses becoming attenuated at higher firing rates (Valentino and Aulisi, 1987; Valentino and Foote, 1987). Thus, the decrease in FS-elicited excitation of LC neurons by AP7 may have been due in part to an increase in spontaneous discharge. Our findings for some cells with AP7, GDEE, scopolamine, and mecamylamine extend these previous observations and indicate that a potential interaction of spontaneous rate and LC neuronal excitability must be considered in pharmacologic investigations of LC activity. It is noteworthy that neither kynurenic acid nor DGG produces this pattern of effects, as both of these agents blunted or blocked FS- and PGi-elicited excitation in LC neurons and tended to decrease spontaneous discharge (though not substantially).

While our results with EAA antagonists implicate an EAA in the mediation of PGi and FS activation of $\mathrm{LC}$, it is possible that these agents have other actions that contribute to antagonism of PGi-evoked responses. For example, it is not yet established what effects these agents have on peptide neurotransmission, and it is therefore possible that DGG or kynurenic acid may have blocked PGI- or FS-evoked excitation of LC in part by interference with excitatory peptides (e.g., substance P or corticotropin-releasing factor). However, neither DGG nor kynurenic acid impaired action potential generation in LC neurons, indicating that the antagonism of excitatory responses by these agents was not the result of a local anestheticlike action. This is consistent with reports by others demonstrating that kynurenic acid and DGG attenuate putative EAA-mediated synaptic transmission by acting at a postsynaptic site and have little or no direct effect on neuronal membrane properties, e.g., resting potential, input resistance, and antidromic excitability (Crunelli et al., 1983, 1987; Ganong et al., 1983; Jacobson and Hamberger, 1986; Jahr and Yoshioka, 1986; Tsumoto et al., 1986). Additional studies are underway to rule out other possible nonspecific actions of DGG and kynurenic acid on excitatory transmission from PGi to LC.

The simultaneous antagonism of both PGi- and FS-induced 
activation of $\mathrm{LC}$ is consistent with our hypothesis that sensory responses of $\mathrm{LC}$ neurons may be mediated by circuits involving projections from PGi to LC as a final link (Aston-Jones et al., 1986; Aston-Jones, 1988). Our findings that antidromically identified LC-projecting PGi neurons are excited by FS (Ennis and Aston-Jones, 1987) and with our preliminary finding that microinjection of the local anesthetic lidocaine into PGi attenuates or abolishes responses of LC neurons to FS (Aston-Jones et al., 1987) are consistent with this hypothesis. While it is also possible that EAA blockade of FS responses in LC neurons with icv kynurenic acid or DGG was effected at a site outside of $L C$ (for example, there are reports that EAA antagonists reduce excitatory synaptic transmission in the spinal cord: Davies and Watkins, 1981; Jahr and Yoshioka, 1986), our preliminary finding that PGi- or FS-evoked activation of LC neurons is abolished after infusion or iontophoresis of kynurenic acid into LC supports our hypothesis that such sensory responses of LC neurons may be mediated through PGi.

\section{Acetylcholine}

The LC stains densely for the degradative enzyme acetylcholinesterase (AchE; Albanese and Butcher, 1980), indicating that these cells may be cholinoceptive. In addition, some PGi neurons stain for markers for cholinergic cells (AchE; Butcher and Woolf, 1984; or choline acetyltransferase: Kimura et al., 1984; M. Shipley, personal communication). Furthermore, pharmacologic studies reveal that LC neurons are excited by acetylcholine, acting predominantly at a muscarinic receptor (Guyenet and Aghajanian, 1979; Engberg and Svensson, 1980). However, the present results indicate that muscarinic receptors do not mediate excitation of LC from PGi inasmuch as scopolamine, at doses previously shown to block excitation of LC neurons involving a muscarinic synapse (Guyenet and Aghajanian, 1979; Engberg and Svensson, 1980), was ineffective on PGi-induced excitation of LC neurons. Similarly, the failure of the nicotinic antagonist mecamylamine to attenuate PGi or FS responses indicates that there may be no nicotinic component in these afferent pathways to $\mathrm{LC}$.

\section{Other pharmacologic agents}

In preliminary experiments, we have examined the effects of other receptor antagonists for neurotransmitters previously reported to influence LC. Intravenous administration of the alpha-2 receptor antagonist idazoxan ( 2 cells), the serotonin receptor antagonists methiothepin (1 cell) or dihydroergotamine (1 cell), or the opiate receptor antagonist naloxone ( 1 cell) had no substantial effect on PGi-evoked excitation.

In conclusion, the present results demonstrate a strong, predominantly excitatory influence of PGi on LC discharge. This excitation appears to be mediated by an EAA, perhaps acting at a kainate-preferring receptor in LC. Further experiments are needed to establish this receptor identification and its location in the LC more firmly.

\section{References}

Aghajanian, G. K. and C. P. VanderMaelen (1982) $\alpha_{2}$-adrenoreceptormediated hyperpolarization of locus coeruleus neurons in vivo. Science 215: 1394-1396.

Aghajanian, G. K., J. M. Cedarbaum, and R. Y. Wang (1977) Evidence for norepinephrine-mediated collateral inhibition of locus coeruleus neurons. Brain Res. 136: 570-577.

Albanese, A., and L. L. Butcher (1980) Acetylcholinesterase and cate- cholamine distribution in the locus ceruleus of the rat. Brain Res. Bull. 5: 127-134.

Andrade, R., and G. K. Aghajanian (1983) Locus coeruleus neurons in vitro: Intrinsic regulation by a calcium-dependent potassium conductance but not by $\alpha_{2}$-adrenoreceptors. J. Neurosci. 4: 161-170.

Andrade, R., and G. K. Aghajanian (1984) Intrinsic regulation of locus coeruleus neurons: Electrophysiological evidence indicating a predominant role for autoinhibition. Brain Res. 310: 401-406.

Andrezik, J. A., V. Chan-Palay, and S. L. Palay (1981a) The nucleus paragigantocellularis lateralis in the rat: Conformation and cytology. Anat. Embryol. 161: 355-371.

Andrezik, J. A., V. Chan-Palay, and S. L. Palay (1981b) The nucleus paragigantocellularis in the rat: Demonstration of afferents by the retrograde transport of horseradish peroxidase. Anat. Embryol. 161. 373-390.

Armstrong, D. M., C. A. Ross, V. M. Pickel, T. H. Joh, and D. J. Reis (1982) Distribution of dopamine-, noradrenaline-, and adrenalinecontaining cell bodies in the rat medulla oblongata: Demonstrated by the immunocytochemical localization of catecholamine biosynthetic enzymes. J. Comp. Neurol. 212: 173-187.

Aston-Jones, G. (1985) Behavioral functions of locus coeruleus derived from cellular attributes. Physiol. Psychol. 13: 118-126.

Aston-Jones, G. (1988) Cellular attributes of locus coeruleus: Implications for attentional processes. In Progress in Catecholamine Research, Vol. B, M. Sandler, ed., Liss, New York (in press).

Aston-Jones, G., and F. E. Bloom (1981) Norepinephrine-containing locus coeruleus neurons in behaving rats exhibit pronounced responses to non-noxious environmental stimuli. J. Neurosci. $1: 887-$ 900.

Aston-Jones, G., S. L. Foote, and F. E. Bloom (1984) Anatomy and physiology of locus coeruleus neurons: Functional implications. In Frontiers of Clinical Neuroscience, Vol. 2, Norepinephrine, M. G. Ziegler and C. R. Lake, eds., pp. 92-116, Williams \& Wilkins, Baltimore.

Aston-Jones, G., M. Ennis, V. A. Pieribone, W. T. Nickell, and M. T. Shipley (1986) The brain nucleus locus coeruleus: Restricted afferent control of a broad efferent network. Science 234: 734-737.

Aston-Jones, G., M. Behbehani, and M. T. Shipley (1987) Lumbar cord innervates a specific subregion of the periaqueductal gray which projects to paragigantocellularis and prepositus hypoglossi, the major afferents to locus coeruleus (LC): Possible connections between periphery and LC. Soc. Neurosci. Abstr. 13: 1336.

Bass, N. H., and P. Lundborg (1973) Postnatal development of bulk flow in the cerebrospinal fluid system of the albino rat: Clearance of the carboxyl- ${ }^{14} \mathrm{C}$ inulin after intrathecal injection. Brain Res. 52: 323332.

Butcher, L. L., and N. J. Woolf (1984) Histochemical distribution of acetylcholinesterase in the central nervous system: Clues to the localization of cholinergic neurons. In Handbook of Chemical Neuroanatomy, Vol. 3: Classical Transmitters and Transmitter Receptors in the CNS, Part 2, A. Bjorklund, T. Hökfelt, and M. J. Kuhar, eds., pp. 1-50, Elsevier, Amsterdam.

Cedarbaum, J. M., and G. K. Aghajanian (1976) Noradrenergic neurons of the locus coeruleus: Inhibition by epinephrine and activation by the $\alpha$-antagonist piperoxane. Brain Res. 112: 413-419.

Cedarbaum, J. M., and G. K. Aghajanian (1977) Catecholamine receptors on locus coeruleus neurons: Pharmacological characterization. Eur. J. Pharmacol. 44: 375-385.

Cedarbaum, J. M., and G. K. Aghajanian (1978) Activation of the locus cocrulcus by peripheral stimuli: Modulation by a collateral inhibitory mechanism. Life Sci. 23: 1383-1392.

Chan-Palay, V. (1977) Indolamine neurons and their processes in the normal rat brain and in chronic diet-induced thiamine deficiency demonstrated by uptake of ${ }^{3} \mathrm{H}$ serotonin. J. Comp. Neurol. 176: 467494.

Chouvet, G. H. Akaoka, and G. Aston-Jones (1988) Serotonin selectively decreases glutamate excitation of locus coeruleus neurons. C. R. Acad. Sci. Paris 306: 339-344.

Collinridge, G. L., S. J. Kehl, and H. McLennan (1983) The antagonism of amino acid-induced excitations of rat hippocampal CA1 neurons in vitro. J. Physiol. (Lond.) 334: 19-31.

Cotman, C. W., and D. T. Monaghan (1987) Chemistry and anatomy of excitatory amino acid systems. In Psychopharmacology: The Third Generation of Progress, H.Y. Meltzer, ed., pp. 197-210, Raven, New York.

Crunelli, V., S. Forda, and J. S. Kelley (1983) Blockade of amino acid- 
induced depolarizations and inhibition of excitatory post synaptic potentials in rate dentate gyrus. J. Physiol. (Lond.) 341: 627-640.

Crunelli, V., J. S. Kelley, N. Leresche, and M. Pirchio (1987) On the cxcitatory post synaptic potential evoked by stimulation of the optic tract in the rat lateral geniculate nucleus. J. Physiol. (Lond.) 384:603618

Davies, J., and J. C. Watkins (1979) Selective antagonism of amino acid-induced and synaptic excitation in the cat spinal cord. J. Physiol. (Lond.) 297: 621-635.

Davies, J., and J. C. Watkins (1981) Differentiation of kainate and quisqualate receptors in the cat spinal cord by selective antagonism with $\gamma$-D (and L)-glutamylglycine. Brain Res. 206: 172-177.

Davies, J., R. H. Evans, A. W. Jones, K. N. Mewett, D. A. S. Smith, and J. C. Watkins (1984) Recent advances in the pharmacology of excitatory amino acids in the mammalian central nervous system. In Excitotoxins, K. Fuxe, P. Roberts, and R. Schwartz, eds., pp. 43-54, Plenum, New York.

Davson, H. (1970) A Textbook of General Physiology, Vol. 1, pp. 724 725, Churchill, London.

Engberg, G., and T. H. Svensson (1980) Pharmacological analysis of a cholinergic receptor mediated regulation of brain norepinephrine neurons. J. Neural Trans. 49: 137-150.

Engberg, G., T. H. Svensson, S. Rosell, and K. Folkers (1981) A synthetic peptide as an antagonist of substance P. Nature 293: 222223.

Ennis, M., and G. Aston-Jones (1986a) A potent excitatory input to the locus coeruleus from the ventrolateral medulla. Neurosci. Lett. 71: 299-305.

Ennis, M., and G. Aston-Jones (1986b) Evidence for self- and neighbor-mediated postactivation inhibition of locus coeruleus neurons. Brain Res. 374: 299-305.

Ennis, M., and G. Aston-Joncs (1987) Two physiologically distinct populations of neurons in the ventrolateral medulla innervate locus coeruleus. Brain Res. 425: 275-282.

Ennis, M., G. Aston-Jones, and V. A. Pieribone (1987) Medullary afferents to locus coeruleus: Physiologic studies. Sixth International Catecholamine Symposium Abstracts, p. 97.

Evans, R. H., A. A. Francis, A. W. Jones, D. A. S. Smith, and J. C. Watkins (1982) The effects of a series of $\omega$-phosphonic $\alpha$-carboxicylic amino acids on electrically evoked and excitant amino acidinduced responses in isolated spinal cord preparations. Br. J. Pharmacol. 75: 65-75

Foote, S. L., F. E. Bloom, and G. Aston-Jones (1983) The nucleus locus coeruleus: New evidence of anatomical and physiological specificity. Physiol. Rev. 69: 844-914.

Forloni, G., R. Grzanna, R. D. Blakely, and J. T. Coyle (1987) Colocalization of $\mathrm{N}$-acetyl-aspartyl-glutamate in central cholinergic, noradrenergic, and serotonergic neurons. Synapse 1:455-460.

Francis, A. A., A. W. Jones, and J. C. Watkins (1980) Dipeptide antagonists of amino acid-induced and synaptic excitation in the frog spinal cord. J. Neurochem. 35: 1458-1460.

Ganong, A. H., T. H. Lanthorn, and C. W. Cotman (1983) Kynurenic acid inhibits synaptic and acidic amino acid-induced responses in the rat hippocampus and spinal cord. Brain Res. 273: 170-174.

Groves, P. M., and C. J. Wilson (1980) Fine structure of rat locus coeruleus. J. Comp. Neurol. 193: 841-852.

Grzanna, R., and M. E. Molliver (1980) The locus coeruleus in the rat: An immunohistochemical delineation. Neuroscience 5: 21-40.

Guyenet, P. G., and G. K. Aghajanian (1979) Acetylcholine, substance $P$, and metcnkcphalin in the locus cocruleus: Pharmacological evidence for independent sites of action. Eur. J. Pharmacol. 53: 319328.

Guyenet, P. G., and B. S. Young (1987) Projections of the nucleus paragigantocellularis lateralis to locus coeruleus and other structures in rat. Brain Res. 406: 171-184.

Harris, E. W., A. H. Ganong, and C. W. Cotman (1984) Long-term potentiation in the hippocampus involves activation N-methyl-Daspartate receptors. Brain Res. 323: 132-137.

Hökfelt, T., K. Fuxe, M. Goldstein, and O. Johansson (1974) Immunohistochemical evidence for the existence of adrenaline neurons in the rat brain. Brain Res. 66: 235-251.
Hökfelt, T., R. Elde, O. Johansson, L. Terenius, and L. Stein (1977) The distribution of enkephalin-immunoreactive cell bodies in the rat central nervous system. Neurosci. Lett. 5:25-31.

Jacobson, I., and A. Hamberger (1986) Effects of kynurenic acid on evoked extracellular field potentials in the rat olfactory bulb in vivo. Brain Res. 386: 389-392.

Jahr, C. E., and K. Yoshioka (1986) Ia afferent excitation of motoneurons in the in vitro new-born rat spinal cord is selectively antagonized by kynurenate. J. Physiol. (Lond.) 370: 515-530.

Jones, A. W., D. A. S. Smith, and J. C. Watkins (1984) Structureactivity relations of dipeptide antagonists of excitatory amino acids. Neuroscience 13: 573-581.

Kimura, H., P. L. McGeer, and J.-H. Peng (1984) Choline acetyltransferase-containing neurons in the rat brain. In Handbook of Chemical Neuroanatomy, Vol. 3: Classical Transmitter and Neurotransmitter Receptors in the CNS, Part 2, A. Bjorklund, T. Hökfelt, and M. J. Kuhar, eds., pp. 51-67, Elsevier, Amsterdam.

Lacey, M. G., and G. IIenderson (1986) Actions of phencyclidine on rat locus coeruleus neurons in vitro. Neuroscience 17: 485-494.

Ljungdahl, A., T. Hökfelt, and G. Nilsson (1978) Distribution of substance P-like immunoreactivity in the central nervous system of the rat. I. Cell bodies and nerve terminals. Neuroscience 3: 861-943.

McLennan, H., and D. Lodge (1979) The antagonism of amino acidinduced excitation of spinal neurons in the cat. Brain Res. 169:8390.

Perkins, M. N., and T. W. Stone (1982) An iontophoretic investigation of the actions of convulsant kynurenines and their interaction with the endogenous excitant quinolinic acid. Brain Res. 247: 184-187.

Perkins, M. N., and T. W. Stone (1985) Actions of kynurenic acid and quinolinic acid in the rat hippocampus in vivo. Exp. Neurol. 88:570579.

Pieribone, V. A., G. Aston-Jones, and M. Bohn (1988) Adrenergic and non-adrenergic neurons in the $\mathrm{Cl}$ and $\mathrm{C} 3$ area project to the locus coeruleus: A fluorescent double labeling study. Neurosci. Lett. 85: 297-303.

Robinson, M. B., K. D. Anderson, and J. F. Koerner (1984) Kynurenic acid as an antagonist of hippocampal excitatory transmission. Brain Res. 309: 119-126.

Rotter, A. N., J. M. Birdsall, P. M. Field, and G. Raisman (1979) Muscarinic receptors in the central nervous system of the rat. II. Distribution of the binding of ${ }^{3} \mathrm{H}$ propylbenzilycholine mustard in the midbrain and hindbrain. Brain Res. Rev. 1: 167-183.

Shimizu, N., Y. Katoh, T. Hida, and K. Satoh (1979) The fine structural organization of the locus coeruleus in the rat with reference to noradrenaline contents. Exp. Brain Res. 37: 139-148.

Surtes, L., and G. G. S. Collins (1985) Receptor types mediating excitatory actions of exogenous L-aspartate and L-glutamate in rat olfactory cortex. Brain Res. 334: 287-295.

Swanson, L. W. (1976) The locus coeruleus: A cytoarchitectonic, golgi and immunohistochemical study in the albino rat. Brain Res. 110 . $39-56$

Swanson, L. W., P. E. Sawchenko, J. Rivier, and W. W. Vale (1983) Organization of ovine corticotropin-releasing factor immunoreactive cells and fibers in the rat brain: An immunohistochemical study. Neuroendocrinology 36: 165-186.

Toomin, C., P. Petrusz, and K. McCarthy (1987) Distribution of glutamate- and aspartate-like immunoreactivity in the rat central nervous system. Soc. Neurosci. Abstr. 13: 1562.

Tsumoto, T., H. Masui, and H. Sato (1986) Excitatory amino acid transmitters in neuronal circuits of the cat visual cortex. J. Neurophysiol. 55: 469-483.

Valentino, R. J., and E. F. Aulisi (1987) Carbachol-induced increases in locus coeruleus spontaneous activity are associated with an altered pattern of response to sensory stimuli. Neurosci. Lett. 74: 297-303.

Valentino, R. J., and S. L. Foote (1987) Corticotropin-releasing factor disrupts sensory responses of brain noradrenergic neurons. Neuroendocrinology 45: 28-36.

Watkins, J. C. (1981) Phamacology of excitatory amino acid receptors. In Glutamate: Transmitter in the Central Nervous System, P. J. Roberts, J. Storm-Mathisen, and G. A. R. Johnston, eds., pp. 1-23, Wiley, New York. 